\title{
PRIVACY AND SENIOR ADOPTION OF ASSISTIVE TECHNOLOGY IN RESIDENTIAL CARE
}

A Dissertation presented to the Faculty of the Graduate School

University of Missouri - Columbia

In Partial Fulfillment

Of the Requirements for the Degree

Doctor of Philosophy

\section{By}

KAREN LYNNE COURTNEY

Dr. Marilyn Rantz, Dissertation Supervisor

MAY 2006 
(c) Copyright by Karen L. Courtney 2006 All Rights Reserved 
The undersigned, appointed by the Dean of the Graduate School, have examined the dissertation entitled:

\section{PRIVACY AND SENIOR ADOPTION OF ASSISTIVE TECHNOLOGY IN RESIDENTIAL CARE}

Presented by Karen L. Courtney

A candidate for the degree of Doctor of Philosophy

And hereby certify that in their opinion it is worthy of acceptance.
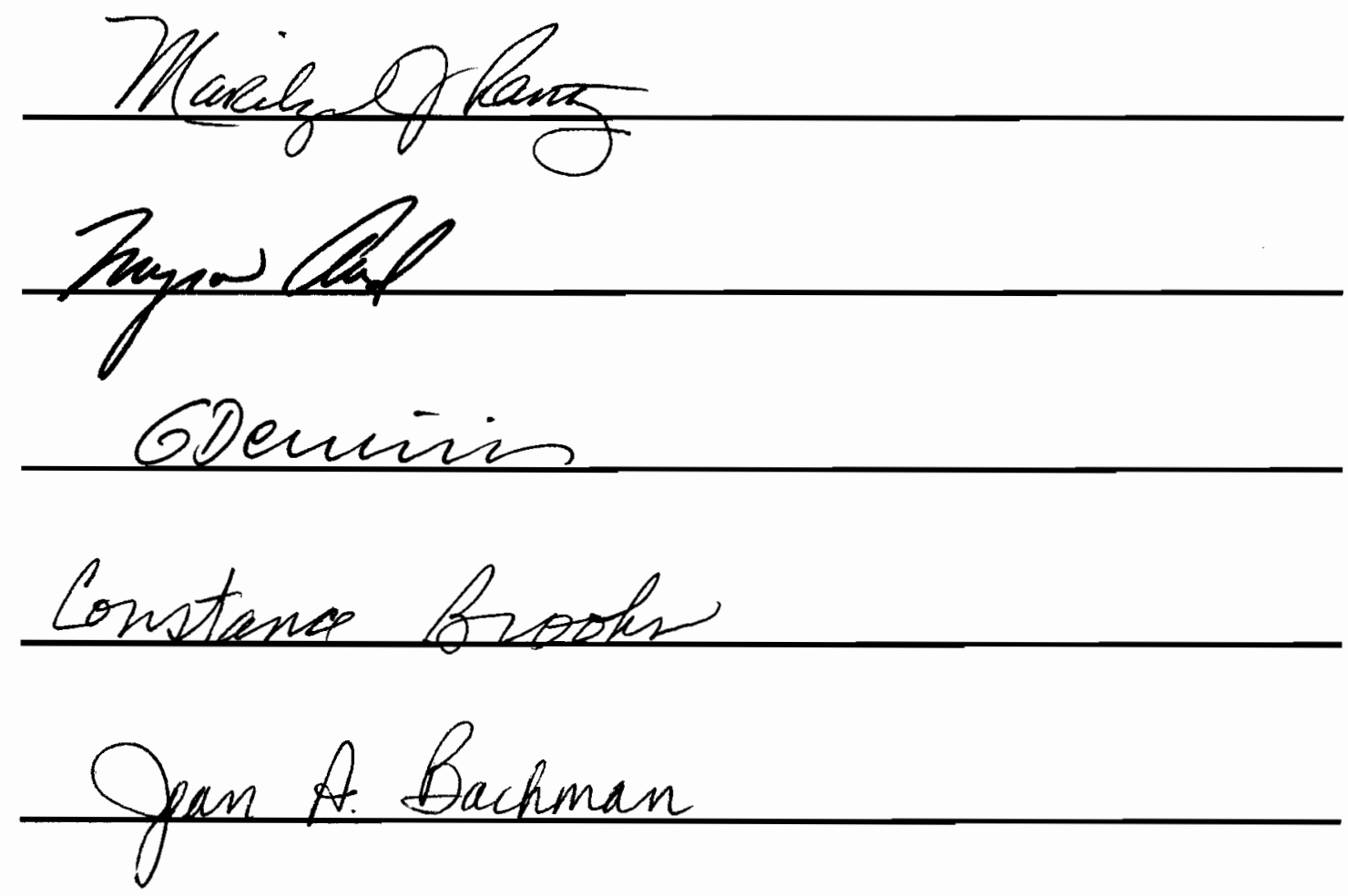


\section{ACKNOWLEDGEMENTS}

I would like to thank the many individuals who have provided invaluable support and help in my academic career.

First, I would like to thank my family: Mary Lynne, David, Courtney and Mary Anne for all their support during this process. You have provided me with the encouragement to continue when I needed it most. I would also like to share a special thank you with my friends, Pam, Beth, Sara, Catherine, Kelly and Rick, who helped keep things in perspective for me. A special thank you goes to Dr. Brian Hensel, who although not called upon, provided much-needed peace of mind as a back-up moderator for the focus groups.

Finally, I would like to thank my colleagues who have supported me in my professional development during these last few years. With Dr. Linda Goodwin’s encouragement, I began this journey. For Drs. Demiris and Rantz, you have been great mentors and invaluable role models in research and teaching. I greatly appreciate the time and wisdom shared with me by my other committee members, Drs. Myra Aud, Jean Bachman and Connie Brooks.

I also am grateful for the opportunities provided to me by the National Library of Medicine Informatics training grant, a research grant from the Alpha Iota Chapter of Sigma Theta Tau, International and the research fellowship from the Center for eResearch at the University of Missouri - Columbia. Their financial and academic support made this journey possible. 
TABLE OF CONTENTS

ACKNOWLEDGEMENTS

LIST OF TABLES

LIST OF FIGURES

ABSTRACT

vii

\section{PART I: RESEARCH PROPOSAL}

Chapter

1. Introduction

Specific Aims

1

Hypothesis

Definitions

Population

Significance

i

$\mathrm{v}$

i 
$\begin{array}{ll}\text { Introduction } & 49\end{array}$

$\begin{array}{ll}\text { Background } & 51\end{array}$

$\begin{array}{ll}\text { Privacy } & 51\end{array}$

Living Environment $\quad 57$

$\begin{array}{ll}\text { Assistive Technologies } & 61\end{array}$

$\begin{array}{ll}\text { Methods } & 64\end{array}$

Design $\quad 64$

$\begin{array}{ll}\text { Sample } & 65\end{array}$

Instrument $\quad 66$

Data Collection Procedure $\quad 66$

$\begin{array}{ll}\text { Analysis } & 67\end{array}$

Findings $\quad 68$

The Meaning of Privacy $\quad 68$

$\begin{array}{ll}\text { The Decision to Adopt an Assistive Technology } & 70\end{array}$

Privacy as a Non-constant Barrier for Assistive Technology Adoption 73

$\begin{array}{ll}\text { Discussion } & 79\end{array}$

Limitations of This Study $\quad 80$

$\begin{array}{ll}\text { Conclusion } & 81\end{array}$

REFERENCES FOR RESEARCH REPORT 83

APPENDICES TO RESEARCH REPORT 91

$\begin{array}{ll}\text { VITA } & 95\end{array}$ 


\section{LIST OF TABLES}

\section{TABLES}

Part I

1. Dimensions of Privacy Found in the Literature

Part II

1. Dimensions of Privacy Found in the Literature 52

2. Private Information or Topics $\quad 69$

3. Factors that Influence Self Perception of Need for Assistive Technology 71

4. Individual-level Privacy Characteristics 75

5. Community-level Privacy Characteristics 77 


\section{LIST OF FIGURES}

\section{FIGURES}

Part I $\quad$ Page

1. Anticipated focus group recruitment 26

$\begin{array}{ll}\text { 2. Potential double layer design example } & 27\end{array}$

3. Data analysis plan 30

Part II

1. Privacy as a weak barrier to assistive technology adoption 74

2. Privacy as a strong barrier to assistive technology adoption 74 


\title{
PRIVACY AND SENIOR ADOPTION OF ASSISTIVE TECHNOLOGY
}

\section{IN RESIDENTIAL CARE}

\author{
Karen Lynne Courtney \\ Dr. Marilyn Rantz, Dissertation Supervisor
}

\begin{abstract}
Within the next twenty years, there is a large increase anticipated in the segment of the population ages sixty five and older and a subsequent increase in demand on residential care facilities. With this expectation, researchers have been exploring the use of assistive information-based technologies in residential care facilities to enhance resident quality of life and safety. Assistive technologies in this context are informationbased technologies that collect and share resident information to health care providers such as nurses or physicians. Little evaluation research exists on user acceptance and effectiveness of assistive technologies in RC facilities (Demiris et al., 2004). Older adults' perceptions of privacy can inhibit their adoption of assistive technologies. This qualitative study used descriptive content analysis of focus group sessions and individual interviews to explore the relationship between privacy, living environment and willingness to adopt assistive technology with older adults living in residential care facilities. The findings from this study indicate that privacy can be a barrier for older adults' adoption of assistive technologies; however their perception of their need for the technology may override their own privacy concerns. Privacy concerns, as a barrier to technology adoption, can be influenced by both individual-level and community-level factors. Further exploration of the factors influencing older adults' perceptions of assistive technology need is necessary.
\end{abstract}




\section{CHAPTER 1}

Introduction

Older adults' perceptions of privacy may inhibit their adoption of assistive technologies that could enhance quality of life and increase home safety. An understanding of the meaning of privacy and its relationship to assistive technology adoption by older adults in residential care (RC) facilities is needed to inform the design of appropriate interventions to increase adoption of such technologies.

\section{Specific Aims}

This study proposes a descriptive, qualitative focus group approach to address the following aims:

1. To explore the meaning of privacy to older adults (ages 65 and above) in residential care facilities

2. To examine how this meaning of privacy affects the willingness of older adults to adopt assistive technologies.

\section{Background}

Patients' concerns over health information privacy have demonstrable, detrimental effects on their interactions with health care providers. Goold and Klipp (2002) suggested patient mistrust can lead to the withholding of information or the disclosure of misleading information to their health care providers. Similarly, another survey noted that one in six persons is "privacy protective" in his or her health care interactions (California HealthCare Foundation, 1999). These "privacy protective" behaviors include: giving incomplete or inaccurate information; asking providers not to 
record certain pieces of information; changing health care provider frequently; not seeking health care; and paying out of pocket for health services (California HealthCare Foundation, 1999). Health care consumers are worried not only that their privacy will be violated but also that "their health information will be used to hurt them" (Goldman \& Hudson, 2000, p. 140).

Additionally, health care providers and researchers cannot assume that health care consumers will necessarily reduce their expectations of privacy based on potential health benefits. In a national survey, $60 \%$ of adults surveyed indicated they would not grant access to their health information in order to participate in a preventive care program (California HealthCare Foundation, 1999). This finding suggests that perceived benefit alone may not mitigate privacy needs or expectations.

Privacy research typically has focused primarily on inpatient, hospital experiences rather than patient experiences within the community (Leino-Kilpi et al., 2001). This is particularly true for older adults over age 65 . Additional research is needed to understand the privacy perceptions of older adults in licensed residential care facilities, such as assisted living, innovative intermediate care or skilled nursing facilities (Hughes, 2004).

The segment of the population that is 65 years and older is expected to grow $54 \%$ between 2000 and 2020 and place additional demand on residential care (RC) facilities (HRSA, 2002). With the growth in the older adult population residing in RC facilities, facilities are increasingly adopting assistive technologies for the well-being of their residents. Assistive technologies in this context are information-based technologies that collect and share resident information to health care providers such as nurses or physicians. Types of assistive technologies that are being developed include: emergency 
help, falls detection, physiological monitoring, cognitive reminder systems and medication management (Demiris et al., 2004). Little evaluation research exists on user acceptance and effectiveness of assistive technologies in these facilities (Demiris et al., 2004).

Additionally, the relationship between the meaning of privacy for this population of older adults and their acceptance of assistive technologies has not been well investigated. Preliminary research has noted associations between lower levels of independence and less positive perceptions of privacy in long term care settings (Schopp et al., 2003). It is not known if assistive technologies would mitigate or exacerbate this association. Potentially, if the privacy behaviors of this group are similar to other adults, these concerns could lead to: underutilization of both health care providers and assistive technologies, increased barriers in diffusion (Rogers, 1995) of assistive technologies and ineffectiveness of interventions that are based on these technologies.

\section{Hypotheses}

Because this is a qualitative, grounded theory study, a pre-defined hypothesis is not being tested within this study. Data codes and themes will be developed inductively. The research question that drives this study is: "How does the meaning and perceptions of privacy by older adults living in residential care facilities affect their willingness to adopt assistive information technologies?" 


\section{Definitions}

Privacy

The definition of privacy is inconsistent within the literature and hence one of the purposes of this study to explore the meaning of privacy for older adults in RC facilities. The definition of privacy for this study will be generated by the participants themselves. Assistive Technologies

Assistive technologies within this study are defined as information-based health devices installed in the RC residents' apartments or "homes". Assistive technologies within this study are limited to information- and health-based technologies that are designed to collect and share residents' health-related information with health care providers, residents, and their designated family members. For the purposes of this study, non-information-based assistive technologies such as canes, chair lifts or motorized wheelchairs, are not included.

The purpose of assistive technologies are to help individuals with tasks they would otherwise be unable to do or to help individuals perform a given task more easily or safely (Cowan \& Turner-Smith, 1999; Dewsbury, Taylor \& Edge, 2001). Assistive technologies in this study may include devices for: emergency communication; falls detection; gait and movement monitoring; cognitive reminder systems and medication management.

\section{Residential Care Facilities}

Within this study residential care facilities include both a traditional, licensed assisted living care facility and an innovative, residential care facility, using an Aging in Place model of care that is licensed as an intermediate care facility. The later residential 
care facility was made possible by the Missouri legislature through waivers and its designation as an "aging in place" demonstration site (Rantz, Marek, Aud, Johnson, Otto and Porter, 2005). Both facilities offer only private apartment homes. Throughout this proposal, the term residential care (RC) facility will be used as a broader, inclusive term for both types of residential care settings.

\section{Population}

The purpose of this study will explore the meanings and perceptions of privacy of older adults (ages 65 and older) residing in RC facilities and residents' willingness to adopt assistive technologies. In this study, participants will be drawn from two RC facilities in a University town in the Midwest. The two facilities have different models of care. One facility is an innovative, licensed, waivered, intermediate care facility using an Aging in Place model, where residents do not need to move as their care levels increase (Marek \& Rantz, 2000). The other facility is a licensed assisted living facility using a more traditional level of service model in which residents are required to move to different facilities as their care needs increase.

\section{Significance}

Older adults' perceptions of privacy may inhibit their adoption of assistive technologies that could enhance quality of life and increase home safety. This study is needed to design appropriate interventions to increase adoption of assistive technologies. The results from this study can inform the work of technology designers, policy makers and health care providers. 


\section{CHAPTER 2}

\section{Review of Literature}

There are three main concepts that underlie this research project: privacy, living environment and assistive technologies. Literature from the CINAHL (1982-2005), MEDLINE (1966-2005) and PSYCHINFO (1985-2005) databases was reviewed using the following MeSH terms: aged; privacy; assisted living facilities; assistive technology; telemedicine; long-term care; and confidentiality. Additional key word searches included: information technology; elderly; and nursing. Only search results with English language abstracts were reviewed. Bibliographies from relevant articles were also handsearched for additional references.

The concepts of privacy, living environment and assistive technologies will be explored in this review. The concepts of privacy and living environment have been linked within the literature as have the concepts of living environments and assistive technologies. Little research however has explored the connections between privacy and assistive technologies within different living environments (Bauer, 2001).

\section{Privacy}

Despite many references in the literature, privacy is a multidimensional concept lacking a universal definition (Lemonidou et al., 2002; Scott et al., 2003a). The terms privacy and confidentiality are often used incorrectly as interchangeable terms by health care providers and occasionally within the literature (Goodwin, Courtney, Kirby, Iannacchione \& Manley, 2002). As an example of the distinction of privacy and confidentiality in health information, privacy refers "to an individual's desire to control 
access" and confidentiality refers to "the obligation of a holder of identifiable personal health information to protect the person's privacy" (Lumpkin, 2000, p. 149). This research is concerned with an individual's desire and ability to control access to one 's self (privacy) rather than mechanisms designed to respect an individual's privacy expectations (confidentiality).

The concept of privacy has been described or categorized in several different ways pertaining to: function (Westin, 1970), type (Westin, 1970; Leino-Kilpi et al., 2001), practices (Leino-Kilpi et al., 2001; Monshi \& Zieglmayer, 2004) and dimension (Leino-Kilpi et al, 2001). Function refers to the purpose privacy serves for an individual (Westin, 1970). The privacy types (Westin, 1970) or perspectives (Leino-Kilpi et al, 2001) are the individual-level mechanisms for achieving privacy within varying group sizes. Privacy practices are the group-level mechanisms for achieving privacy and are culturally defined (Leino-Kilpi et al., 2001; Monshi \& Zieglmayer, 2004). Privacy dimensions are the descriptive categorizations of privacy concerns (Leino-Kilpi et al, 2001). Each of these different descriptions of privacy provides insight into the multidimensional concept of privacy. Privacy Functions

The distinctions between informational privacy and confidentiality made above are consistent with the classic view of the functions or purpose of privacy. Westin (1970) proposed four key functions of privacy: 1) personal autonomy, 2) emotional release, 3) self-evaluation and 4) limited and protected communication. Personal autonomy as a function of privacy is tied to the concepts of self-identity and self-independence (Westin). Westin refers to the ability to relax from social roles as an "emotional release" function 
of privacy. Self-evaluation as a function of privacy is the opportunity to reflect on experience and strategize future actions without the scrutiny of others (Westin). The selfevaluation function of privacy often requires the physical separation from others. The limited and protected communication function in contrast involves the controlled interaction with others (Westin).

A consistent theme within Westin's four functions of privacy is the individual's control over other people's access to oneself (Altman, 1970). In interviews with nursing home residents, personal autonomy, emotional release and self-evaluation functions were identified by residents as benefits of privacy (Roosa, 1982).

\section{Privacy Types}

Westin (1970) also proposed four types or individual means of achieving privacy in addition to the functions. These types include: solitude, intimacy, anonymity, and reserve (Westin). Solitude as a privacy type means physical isolation from others (Westin). Intimacy involves small groups that separate themselves from the larger group (dyads, triads) (Westin). Anonymity is to be separate from but yet surrounded by others or "lost in a crowd" (Westin). Reserve is the construction of a "psychological barrier against unwanted intrusion" (Westin, p. 32) to ignore others either in small or large groups.

In separate studies of nursing home residents, the solitude (Ray-Degges, 1995; Roosa, 1982) and reserve (Ray-Degges, 1995) types were supported as mechanisms for achieving privacy. These types of privacy are also important as they stress how individual mechanisms for achieving privacy vary with the differences in social unit size (Altman, 1970). 


\section{Privacy Practices}

The practices of privacy can also vary considerably within different cultural contexts. In their study of health practices in Sri Lanka, the researchers found that many of the privacy protections they employed were not acceptable to their Sri Lankan participants (Monshi \& Zieglmayer, 2004). In this study, the practices of using a separate, private room and isolating participants from other family members for interviews made participants uncomfortable. Privacy is a multi-dimensional concept and is culturally defined in practice.

\section{Privacy Dimensions}

Despite a lack of a universal definition for privacy as a concept, there are several descriptive dimensions of privacy which are consistent within the literature. Conceptually, privacy concerns are often seen in four distinct dimensions: psychological, social, physical and informational (Leino-Kilpi et al., 2001). Each of these dimensions of privacy can result in different privacy responses to situations. Explanations of each privacy dimension from the literature are included in Table 1.

\begin{tabular}{|l|l|}
\hline $\begin{array}{l}\text { Privacy } \\
\text { Dimension }\end{array}$ & Explanation \\
\hline Psychological & $\begin{array}{l}\text { Refers to the maintenance of a personal identity through individual } \\
\text { control of cognitive and affective behavior (Hughes, 2004; Leino-Kilpi } \\
\text { et al., 2001). }\end{array}$ \\
\hline Social & $\begin{array}{l}\text { Refers to the individual's control over their social contacts (Leino-Kilpi } \\
\text { et al., 2001). }\end{array}$ \\
\hline Physical & $\begin{array}{l}\text { Refers to the individual's control of physical access to oneself (Leino- } \\
\text { Kilpi et al., 2001). Physical access can also include the personal space or } \\
\text { territory of an individual (Leino-Kilpi et al., 2001). }\end{array}$ \\
\hline Informational & $\begin{array}{l}\text { Refers to the individual's control over the collection and distribution of } \\
\text { personal information (Hughes, 2004; Leino-Kilpi et al., 2001). }\end{array}$ \\
\hline
\end{tabular}

Table 1: Dimensions of Privacy Found in the Literature 


\section{Psychological privacy.}

The psychological dimension of privacy refers to the maintenance of a personal identity through individual control of cognitive and affective behavior (Hughes, 2004; Leino-Kilpi et al., 2001). The concepts of psychological privacy and identity have been linked within the literature (Altman, 1975). Psychological privacy is often presented as a condition for individual growth and development (Leino-Kilpi et al., 2001). Psychological privacy is tied to self-observation and self-identity (Altman). "But it is not the inclusion or exclusion of others that is vital to self-definition; it is the ability to regulate contact when desired." (Altman, p. 50) Violation of psychological privacy can be a serious loss of individual control in addition to the unintended release of information (Altman).

\section{Social privacy.}

Social privacy refers to the individual's control over their social contacts (LeinoKilpi et al., 2001). Social privacy can be seen in Westin's states of privacy which describe the interactions with various sizes of groups (Leino-Kilpi et al.). Hughes (2004) noted that living environments can enhance or detract from an individual's sense of social privacy. "In communal environments older consumers have little influence over who they have contact with and inevitably not all interaction is likely to be pleasant." (Hughes, 2004, p. 112)

\section{Physical privacy.}

Physical privacy refers to the individual's control of physical access to oneself (Leino-Kilpi et al., 2001). Physical access can also include the personal space or territory 
of an individual (Leino-Kilpi et al.). Leino-Kilpi et al. suggested that physical privacy can be tied to Westin's privacy function of "emotional release".

In Ray-Degges' (1995) study of nursing home residents, she found that the type of room or living environment influenced resident's definitions of privacy. In this study, residents with private rooms were more likely to define privacy as solitude or physical aloneness; however residents with semi-private rooms defined privacy as controlling access to oneself. Residents in both room types described manipulating the physical arrangements of the room (furniture, curtains, etc) to enhance their privacy (RayDegges). Archea (1977, p. 121) suggests that "the arrangement of the physical environment" influences personal behavior and perceptions of privacy through the distribution of visual information. Likewise it has been suggested that the physical space and structure of the home environment facilitate privacy (Angus, Kontos, Dyck, McKeever \& Poland, 2005).

Physical privacy has also been linked to issues of personal space and territoriality (Randers \& Mattiasson, 2000; Tamm, 1999). In interviews with older adults within an in-patient facility, personal property and the immediate personal space emerged as extensions of the older adult's identity (Randers \& Mattiasson, 2000). The respondents perceived the unannounced entrance of others into their personal space and the uninvited handling of personal items to be privacy or integrity violations (Randers \& Mattiasson). Likewise in a survey of nursing home residents $(\mathrm{n}=56)$, Roosa (1982) noted that areas surrounding a resident's bed were considered to be "owned" by the resident. Residents expressed that their privacy had been violated when owned areas were used or examined by others (Roosa). 


\section{Informational privacy.}

Informational privacy is the individual's control over the collection and distribution of personal information (Hughes, 2004). Within the last decade, concerns about informational privacy and confidentiality have become more prominent within both scholarly and public discourse. In the United States, the implementation of privacy and security regulations associated with the Health Insurance Portability and Accountability Act of 1996 PL 104-191 (HIPAA) has prompted greater consumer, researcher and health care provider interest in informational privacy and confidentiality (Centers for Medicare and Medicaid Services, 2003).

Additionally, it has been suggested that obtaining information about a person against their will also constitutes a violation of informational privacy (Leino-Kilpi et al., 2001). Potentially, this aspect of informational privacy could play a role in an individual's view of information-based assistive technologies which collect and share information, such as one's activity levels, sleeping patterns or treatment adherence, with health care providers.

These different dimensions of privacy can lead to different individual privacy needs. Furthermore, different situations can stimulate privacy needs based on one or more of the dimensions of privacy. An example of the complex interaction of different dimensions of privacy within one situation is Bauer's (2001) discussion of how homebased, telemedicine applications can simultaneously enhance physical privacy and increase the risk of informational privacy violations. In his discussion, he notes that the use of telemedicine applications could decrease the physical intrusion of health care providers into the home setting while also introducing the risk of privacy violation 
through inappropriate or unintentional information sharing through the information technology used (Bauer).

\section{Consequences of Perceived Privacy Loss}

However, even prior to HIPAA implementation, patient privacy concerns were well documented. In 2001, Lester reported that only $12 \%$ of patients were unconcerned about their privacy and uses of their personal health information (PHI). Furthermore, health care consumers are viewing technological advances in record keeping with skepticism. As early as 1997, former Secretary of Health and Human Services Shalala noted that nearly $75 \%$ of citizens are at least somewhat concerned about how computerization of their health records will negatively affect their privacy (Shalala, 1997). In a study of ambulatory care patients and parents of pediatric patients $(n=92)$, $80 \%$ of respondents indicated they cared "a lot" about their information privacy (Goodwin et al., 2002).

Despite consumer concern over potential health information privacy violations, in a national survey $(n=1000)$ only a small number of health care consumers $(18 \%)$ believe they personally have had their health information privacy violated (California HealthCare Foundation, 1999). Of this group, however, nearly half said the violation caused personal embarrassment or harm (California HealthCare Foundation). Health care consumers are worried not only that their privacy will be violated but also that "their health information will be used to hurt them" (Goldman \& Hudson, 2000, p. 140).

Patient's concerns over health information privacy have demonstrable, detrimental effects on their interactions with health care providers. As a result of patient mistrust, patients may withhold information or disclose misleading information to their 
health care providers (Goold \& Klipp, 2002). This mistrust can also lead to "privacy protective" behaviors when interacting with health care providers. In one national survey, one in six persons described using "privacy protective" behaviors in their health care interactions (California HealthCare Foundation, 1999). These "privacy protective" behaviors include: giving incomplete or inaccurate information; asking providers not to record certain pieces of information; frequent health care provider changes; avoidance of the health care system; and paying out of pocket for health services (California HealthCare Foundation). Consumers, who believe their health information privacy has been violated, were four times more likely to engage in privacy protective behaviors than those who do not believe their information privacy has been violated (California HealthCare Foundation).

Prior research with focus groups has confirmed these privacy protective behaviors in adult primary care patients (Deshefy-Longhi, Dixon, Olsen \& Grey, 2004). In this study, patients shared that they had made requests for not documenting conversations due to privacy concerns and they indicated a strong desire to control access to their information (Deshefy-Longhi et al., 2004). Likewise privacy protective behaviors were observed in Malcolm's (2005) study of adults in shared rooms within an inpatient facility. The situation-dependent privacy perceptions of respondents influenced whether or not they would limit or withhold information with their health care providers (Malcolm).

Potential health benefits may not necessarily reduce adults' expectations of privacy. Sixty percent of adult survey respondents indicated they would not grant access to their health information in order to participate in a hospital preventive care program (California HealthCare Foundation, 1999). This finding suggests that perceived benefit 
alone may not mitigate privacy needs or expectations. "Protecting privacy is critical to promoting health, fostering access to care, and improving the quality of care for individuals and their communities." (Goldman \& Hudson, 1999, p.14)

\section{Differences in Privacy Perceptions}

Health care providers and patients often have different perceptions of privacy even within the same situation (Deshefy-Longhi et al., 2004). In a five country comparison of patients' $(n=1,454)$ and nurses' $(n=1,280)$ perceptions of privacy, researchers found significant variation between the two (Lemonidou, Leino-Kilpi et al., 2003). Surprisingly, hospital patients in four of five countries (Finland, Spain, Germany and Scotland) perceived that they had more privacy in the hospital setting than did their nurses (Lemonidou, Leino-Kilpi et al., 2003). Additionally, patients in the four of five countries (Finland, Spain, Germany and Scotland) rated the realization of privacy by dimension (informational, social and physical) higher than the nurses (Lemonidou, Leino-Kilpi et al., 2003).

In contrast within the same study, in Greece however, nurses felt that patient privacy was more protected more often than patients did (Lemonidou, Leino-Kilpi et al., 2003). In a similar study of older adults in long-term care facilities in Greece, again the patients $(\mathrm{n}=195)$ rated the perception of actual privacy as lower than their nurses $(\mathrm{n}=$ 218) (Lemonidou et al., 2002). Based on the noted differences in privacy perceptions between health care provider and patients, it is apparent that the appropriate information source for privacy perceptions is the patient rather than health care provider report.

Furthermore, patients and nurses vary on both the perceived importance of the individual dimensions of privacy as well as their perceptions of actual patient privacy 
(Lemonidou, Leino-Kilpi et al., 2003). In the study by Lemonidou, Leino-Kilpi et al. (2003), the patients rated informational and social privacy practices as more important whereas the nurses rated physical privacy practices as more important. These findings suggest that patient values and expectations are critical in planning appropriate privacy practices. As in the above example, privacy interventions may be executed well, but may not be the right intervention from the patient's perspective. Each of these dimensions of privacy can result in different privacy behaviors and may influence an individual's response in different ways.

\section{Living Environment}

Home

Williams (2002) argued that the meaning of place is a key to understanding the importance of that place. The concept of home has been linked to privacy as a specific location where privacy and identity are protected (Rousch \& Cox, 2000; Tamm, 1999; Williams, 2004). Additionally, the concept of home includes the home as a familiar place of comfort and the home as the center of everyday experiences (Rousch \& Cox, 2000; Tamm, 1999; Williams, 2004). All three of these dimensions of home are linked to familiar routines, physical arrangements and the social structure of the home (Rousch \& Cox). Often residents idealize their personal concept of home (Rousch \& Cox). The actual experience of home may be considerably different than residents' ideal home especially as personal health conditions change (Rousch \& Cox).

The inclusion of health services within the home environment can influence changes in residents' beliefs, experiences and meaning of home (Angus et al., 2005; Ellefsen, 2002; Tamm, 1999; Williams, 2002). Therefore when the home is within a 
residential care (RC) facility, the beliefs, experiences and meanings associated with personal identity and privacy may also be affected.

\section{Residential Care and Assisted Living}

This study includes both a traditional, licensed assisted living care facility and an innovative, residential care facility, using an Aging in Place model of care that is licensed as an intermediate care facility. Both facilities contain only private apartment homes rather than shared rooms. Throughout this proposal, the term residential care (RC) facility will be used as a broader, inclusive term for both types of residential care settings.

Residential care facilities aim to provide personal and health-related services within a homelike environment (Wilson, 1996). The goals of RC facilities typically include a commitment to maximizing resident "dignity, privacy, independence and autonomy" (Wilson, p. 3). Residents within RC facilities are generally considered to be dwelling in the community rather than in an institution (skilled nursing or long-term care facilities) (Hawes, Phillips, Holan, Sherman and Hutchinson, 2005; Phillips, Holan, Sherman, Spector and Hawes, 2005; Wilson, 1996)

\section{Definition.}

In this proposal both residential care sites, although they have different facility designations (licensed assisted living and licensed intermediate care facility with waivers) and different care models, they both can be described using the general definition of assisted living facilities. The Assisted Living Quality Coalition provides the most commonly used definition for assisted living facilities from the Assisted Living Quality Coalition, as quoted within Phillips et al. (2005, p. 374). 
A congregate residential setting that provides or coordinates personal services, 24-hour supervision, and assistance (scheduled and unscheduled), activities, and health related services; designed to minimize the need to move; ... to accommodate residents' changing needs and preferences; ... to maximize residents' dignity autonomy, privacy, independence and safety; and... to encourage family and community involvement (p.65).

This common definition focuses on twenty four hour available services, a facilitation for aging in place, and an emphasis on independence and privacy within a homelike setting (Hawes et al., 2005). There is considerable variation however, in how facilities that are designated as assisted living facilities provide the services or the infrastructure to meet those common goals (Hawes et al., 2005; Phillips et al., 2005). In their examination of rural assisted living facilities, Hawes et al. found that there were five distinct groups of assisted living facilities, which represented varying combinations of service levels and resident privacy. In their study, sixty percent of assisted living facilities offered "a combination of low services and low privacy, or offered either minimal services or minimal privacy" (Hawes et al, p. 135).

Although a goal of RC facilities may be to enhance resident independence, autonomy, privacy and safety, typically facilities will transfer residents to a different facility when their health care needs increase (Marek \& Rantz, 2000; Rantz, Marek, Aud, Johnson et al., 2005). This transition to skilled nursing facilities or nursing homes has been associated with resident's health decline (Marek \& Rantz, 2000). Community 
dwelling residents can be fearful of forced relocation to nursing homes (Rantz, Marek, Aud, Johnson et al., 2005).

\section{Aging in Place Model.}

In response to concerns about changes in older adults' health status and fears regarding relocation, a newer model of care delivery is being emphasized within RC facilities, “Aging in Place” (Marek \& Rantz, 2000; Marek, Rantz \& Porter, 2004; Rantz, Marek, Aud, Johnson et al., 2005; Rantz, Marek, Aud, Tyrer et al., 2005). In contrast to traditional models of care, RC facilities using an "Aging in Place" model emphasize the care coordination of services to allow senior residents to stay in their chosen homes even as their health care needs change over time (Marek \& Rantz, 2000; Rantz, Marek \& Zwygart-Stauffacher, 2000).

The goals of an Aging in Place model in RC facilities are to "help older people stay healthier and active longer, avoid expensive and debilitating hospitalizations and for most residents, avoid relocation to a nursing home" (Rantz, Marek, Aud, Tyrer et al., 2005, p.41). Use of the Aging in Place model with a community dwelling seniors ( $\mathrm{n}=$ 156), demonstrated significantly better clinical outcomes (cognition, depression, activities of daily living and incontinence) for community-based seniors receiving Aging in Place services $(n=78)$ versus a matched set of nursing home residents $(n=78)$ who were not receiving Aging in Place services (Marek, Popejoy, Petroski, Mehr, Rantz \& Lin, 2005).

The Aging in Place model rests on an assumption of an environment that is supportive of resident independence (Marek \& Rantz, 2000). The use of the Aging in 
Place model in RC facilities can also influence the beliefs, experiences and meanings associated with personal identity and privacy of senior residents.

\section{Effects on privacy.}

The living environment of a RC facility affects residents' privacy needs through a variety of dimensions. RC facilities are designed to provide "home-like" residential environments (Spitzer, Neuman \& Holden, 2004; Wilson, 1996). "Resident care in assisted living more frequently evolves from a residential rather than medical model." (Spitzer et al., 2004, p. 27) In a study of 686 nursing home residents, residents' perceptions of "feeling at home" were related to their perceptions of privacy (deVeer \& Kerkstra, 2001). Hughes (2004) suggested that the "home" is part of personal identity and as such a transition to an residential care facility can represent a challenge to one's sense of psychological privacy as well as physical and informational privacy.

Tamm (1999) noted that re-arrangement of furniture by others or introduction of technological aids into the home environment can be a significant intrusion and affect an individual's sense of identity and privacy. This finding is consistent with Archea's (1977, p. 129) assertion that "physical environment is an instrument which is used selectively to inhibit or facilitate the flow of interpersonal information." Potentially, assistive technologies can affect privacy through the rearrangement of personal space to accommodate the technology or through more subtly changing the perception of the home from private space into more public space. Tamm (1999) noted that older adults' perceptions of technologies introduced into the home environment have not been well studied. 
Preliminary research has noted associations between lower levels of independence and less positive perceptions of privacy in long term care settings (Schopp et al., 2003). It is not known if assistive technologies would mitigate or exacerbate this association. Potentially, if the privacy behaviors of this group are similar to other adults, these concerns could lead to: underutilization of both health care providers and assistive technologies, increased barriers in diffusion (Rogers, 1995) of assistive technologies (Rogers, 1995) and ineffectiveness of interventions that are based on assistive technologies.

\section{Assistive Technologies}

\section{Definitions}

Assistive technologies are defined as information-based health devices or systems installed in the RC residents' apartments or "homes". These technologies collect and share resident information to health care providers such as nurses or physicians. The purpose of assistive technologies are to help individuals with tasks they would otherwise be unable to do or to help individuals perform a given task more easily or safely (Cowan \& Turner-Smith, 1999).

Assistive technologies in these settings may include devices for: emergency communication; falls detection; gait and movement monitoring; cognitive reminder systems and medication management (Demiris et al, 2004; Dewsbury, Sommerville, Rouncefield \& Clarke, 2002; Miskelly, 2001). Examples of assistive technologies can be found both within the telehealth and "smart home" literature.

Early development in smart homes focused on homes designed with embedded non-obtrusive automatic functions and systems controlled by the user (Rialle, Duchene, 
Noury, Bajolle \& Demongeot, 2002; Stefanov, Bien \& Bang, 2004). These early examples emphasized systems to enhance "comfort, energy savings and security for residents" (Stefanov et al., 2004, p. 228). Recent research in smart homes has begun to include telehealth applications and include non-obtrusive health monitoring applications (Rialle et al., 2002; Stefanov et al., 2004).

Smart home, assistive technologies are being installed within private residences (Magnusson \& Hanson, 2005; Rialle et al., 2002; Stefanov et al., 2004; Suzuki et al., 2004) and now also within residential care facilities (Rantz, Marek, Aud, Tyrer et al., 2005). The arguments for bringing these assistive technologies into community homes are to enhance residents quality of life; to help maintain them living at home and to reduce health care costs through prevention and early intervention (Magnusson \& Hanson, 2005; Rantz, Marek, Aud, Tyrer et al., 2005; Stefanov et al., 2004). In a cost analysis of assistive technologies to support older adults and their family caregivers ( $\mathrm{n}=$ 34 families), researchers found that the average cost savings per family per year was 96,000 SEK (Swedish Crowns) or $\$ 10,480$ (Magnusson \& Hanson, 2005). The majority of estimated cost savings were a result of avoidance of nursing home placement (Magnusson \& Hanson, 2005).

The inclusion of these types of assistive technologies within residential care facilities is believed to be a mechanism to extend resident functional status and delay resident decline over time (Rantz, Marek, Aud, Tyrer et al., 2005). The inclusion of assistive technologies within the $\mathrm{RC}$ environment is one potential mechanism for supporting the Aging in Place model of care (Rantz, Marek, Aud, Tyrer et al., 2005). 


\section{Effects on privacy}

The ethics literature on information technologies within the home environment suggests that privacy should be an important ethical consideration for implementation and evaluation of these information systems (Bauer, 2001; Magnusson \& Hanson, 2003). "The private domain of the home becomes a highly porous, public node where medical information and communication technologies merge.” (Bauer, 2001, p. 140) Limited existing research on assistive technologies includes the concept of privacy in technology evaluation. The preliminary research in this area suggests that perceptions of privacy may be a barrier for the adoption of assistive technologies (Demiris et al., 2004; Magnusson \& Hanson, 2003).

In a multi-country study of the implementation of information technologies for frail older adults in their own homes $(\mathrm{n}=39)$, issues of privacy arose with videophone technologies (Magnusson \& Hanson, 2003). Participants in the study described placing screens in front of the videophones to block visual access to the rest of the room (Magnusson \& Hanson, 2003). Additionally, participants described privacy concerns about the location of the videophones within the home (both in central areas such as the living room and in private areas such as the bedroom) and about who controls the opening of the communication line or if it was a continuous "open-line" (Magnusson \& Hanson).

Residents of a traditional assisted living facility indicated that privacy was a potential concern about using assistive technology with a video monitoring component (Demiris et al., 2004). Some of the residents did indicate that with changes to the video display, this assistive technology might be more acceptable (Demiris et al.). This finding 
suggests that the type of assistive technology and the type of information it collects and shares might be important factors in privacy concerns or in the decision to adopt.

Further research is needed to explore the relationships between privacy, living environments and older adult adoption of assistive technologies. Preliminary links have been drawn in the literature between privacy and living environments or assistive technologies. Likewise, assistive technologies and living environments have been linked within the literature. Little research however has explored the connections between privacy and assistive technologies within different living environments (Bauer, 2001).

Older adults' perceptions of privacy may inhibit their adoption of assistive technologies that could enhance quality of life and increase home safety. An understanding of how the different dimensions of privacy affect older adults' privacy perceptions in this setting, is needed to understand current adoption of assistive technologies by this group and in the future develop appropriate interventions to enhance adoption (Bauer, 2001; Magnusson \& Hanson, 2003).

Existing evaluation literature on assistive technologies often focuses on the potential benefits or usability of the technology and pays inadequate attention to the concerns of potential users or their willingness to adopt the technology. Several studies have suggested that not all older adults or families may uniformly benefit from assistive technologies (Magnusson \& Hanson, 2005; Rantz, Marek, Aud, Tyrer et al., 2005). Knowledge of how privacy concerns affect older adults' willingness to adopt new technologies is one necessary component for identifying which seniors might benefit from the technology. Without this understanding of privacy concerns and willingness to 
adopt technologies, researchers may not be able to effectively develop assistive technology interventions and target the appropriate populations.

Not only do interventions to improve or maintain older adult health status need to be implemented properly, but the interventions need to be the right interventions from the older adult's perspective. This study, which will explore senior privacy concerns and the willingness to adopt assistive technology within an residential care living environment, will provide valuable knowledge for the development of assistive technology interventions and will inform the practice of health care providers, technology developers and policy makers.

\section{CHAPTER 3}

\section{Methods \\ Design}

This proposed study used a descriptive focus group approach. A qualitative descriptive approach was chosen for this study because the research question pertains to the meanings of privacy and its effect on adoption of assistive technologies. The goal of this study was to produce a descriptive summary of an experience or decision event. This summary generated the groundwork for future interpretative enquiries such as grounded theory or phenomenology studies (Sandelowski, 2000).

Focus groups have been selected because we were interested in the complex interaction between privacy and assistive technology adoption within residential care (RC) facilities. The focus group approach allowed us to explore belief, feeling and action in this area (Carey, 1994). Additionally, the group interaction could have generated a richer data set as participants could have also responded to each others' beliefs, feelings 
and experiences, as well as describe their own (Carey, 1994). Focus groups had been successfully used for in-depth probing of privacy for primary care patients (DeshefyLonghi, Dixon, Olsen \& Grey, 2004 and for exploration of attitudes and beliefs about assistive technololgy (Demiris et al., 2004).

\section{Sample: Size and Sampling Procedure}

We used four focus groups. The estimated number of participants was based on other focus group samples studying privacy or health care access (Da Silva, et al., 2002; Garside, et al., 2002; Lichtenstein, 2003). The general rules for the number of participants and groups are: 4 to 12 participants per focus group and 3-6 focus groups per study (Krueger \& Casey, 2000; Morgan, 1992). The actual number of focus groups depended on data saturation. Data saturation was reached when no new themes or issues emerged from group sessions.

Focus group members were recruited from older adults in two mid-western RC facilities as described earlier. Adults ages sixty-five or older with varying levels of physical independence were recruited. None of the participants had court-appointed legal guardians. Figure 1 shows the initial plan for focus group recruitment using a multiple category design (Kruger \& Casey, 2000).

\begin{tabular}{|l|l|c|c|c|}
\hline \multicolumn{1}{|c|}{ RC model } & Participants & \multicolumn{3}{|c|}{ Planned Focus Group } \\
& & \multicolumn{2}{|c|}{ Sessions } \\
\hline Aging in Place & Adults over 65 & $\bullet$ & $\bullet$ & $\begin{array}{c}\circ \\
\text { Potential }\end{array}$ \\
\hline Traditional & Adults over 65 & $\bullet$ & $\bullet$ & $\begin{array}{c}\circ \\
\text { Potential }\end{array}$ \\
\hline
\end{tabular}

Figure 1: Anticipated focus group recruitment 
This study used theoretical sampling techniques to enrich data collection.

Sandelowski (1995, p. 181) described the goal of purposive sampling as "while the sample is statistically non-representative, it is informationally representative." Using this philosophy, we conducted each focus group one at a time and our recruitment efforts for the future groups were informed by the results of each preceding group. Our purposive sampling initially focused on the residential care facility model of care and resident independence.

Other categories of residents could have emerged as important and would have influenced the recruitment strategies for each subsequent group. For example, if during a focus group, it became apparent that having a mixed-gender focus group was affecting participation, then future focus groups would have been single-gender groups. An example of how the focus group design would have changed to a double layer design in the above scenario is in Figure 2.

\begin{tabular}{|l|l|c|c|c|}
\hline \multicolumn{1}{|c|}{ RC model } & Participants & \multicolumn{3}{|c|}{ Planned Focus Group } \\
& & \multicolumn{2}{|c|}{ Sessions } \\
\hline Aging in Place & Adults over 65 & $\bullet$ & & \\
\cline { 2 - 5 } & Men over 65 & $\bullet$ & $\begin{array}{c}0 \\
\text { Potential }\end{array}$ & $\begin{array}{c}\circ \\
\text { Potential }\end{array}$ \\
\cline { 2 - 5 } & Women over 65 & $\bullet$ & $\begin{array}{c}\circ \\
\text { Potential }\end{array}$ & $\begin{array}{c}\circ \\
\text { Potential }\end{array}$ \\
\hline Traditional & Adults over 65 & $\bullet$ & & \\
\cline { 2 - 5 } & Men over 65 & $\bullet$ & $\circ$ & $\circ$ \\
& Women over 65 & $\bullet$ & $\begin{array}{c}\circ \\
\text { Potential }\end{array}$ & $\begin{array}{c}\circ \\
\text { Potential }\end{array}$ \\
\cline { 2 - 5 } & Potential \\
\hline
\end{tabular}

Figure 2: Potential double layer design example

Participants were recruited using flyers on bulletin boards within each residence. A secondary targeted recruitment plan that included announcements within the weekly 
residents' council meetings or invitations in residents' personal mailboxes was used. The primary recruitment strategy had been used for other focus groups within these facilities.

Participant burden was minimal. Focus groups met once for approximately sixty minutes. Prior focus group recruitment in these facilities had been most successful in focus groups held immediately prior to or after a meal. If other times, not adjacent to meal times were used for focus group scheduling, snacks would have been provided to participants because food can have a dual benefit as both an incentive for participation and as a means to begin group socialization (Krueger \& Casey, 2000).

\section{Instrument}

A copy of the instrument is found in Appendix A. This instrument was a semistructured series of questions to guide the facilitator during the focus group sessions. This study borrowed constant comparative analysis from the grounded theory tradition, and therefore as focus groups were conducted, the interim findings generated modifications to the interview guide. The interview guide was developed in conjunction with the principles in Kruger's Developing Questions for Focus Groups (1998) and Stanfield's The Art of Focused Conversation (2000). Questions from the instrument were pilot tested during a focus group in the innovative intermediate care facility in November. The results of this pilot work were not included in the full study. Questions 1 through 5 addressed Specific Aim 1 and questions 6 through 15 addressed Specific Aim 2.

\section{Data Collection Procedure}

Following informed consent and a brief study introduction, the facilitator began the session using the interview guide. Each focus group was audio taped and field notes were taken. Focus group discussions lasted until the respondents had nothing new to add 
or sixty to ninety minutes. Following the discussion period, the facilitator summarized the main points from the discussion and thanked the residents for their participation. This summary served as a member check to ensure that we had captured what the participants intended.

\section{Method of Analysis}

Although many qualitative approaches to these data could have been considered, qualitative content analysis was appropriate for the qualitative descriptive goal of this proposed study (Sandelowski, 1995). A pre-determined coding scheme was not used for coding the data. Data codes and themes were inductively generated. The goal of the qualitative content analysis was a summary of the information gleaned from the analyses of data. Analysis of the data was performed by the PI and validity of interpretations were checked by other members of the research team. Interpretations were validated with the each new focus group session (Krueger, 1998b). The PI used QSR N6 software to assist with data management and analysis.

Carey (1994) warned of "group" effects (censoring and conformity) and "social loafing" (limited participation) when using a focus group methodology. As the analysis of each group session informed the practices of the next group session, this review helped the research team to proactively correct for these weaknesses in future sessions.

In borrowing from the grounded theory tradition of constant comparative analysis, we performed content analysis of the data set from each focus group and these results informed the subsequent focus group session (Creswell, 1998). In grounded theory, in constant comparative analysis, data are analyzed in multiple levels, the individual text line, the clustering of ideas, and the pulling together of the concept or theory (Benoliel, 
1996; Creswell, 1998). Because this study was focused on exploration of the meaning of privacy and its relationship with the adoption of assistive technologies rather than development of a theory of behavior, we used the first two levels of analysis, the individual text line (open coding) and the clustering of ideas or themes (axial coding) from the grounded theory tradition. The proposed steps for analysis are included in Figure 3 below.

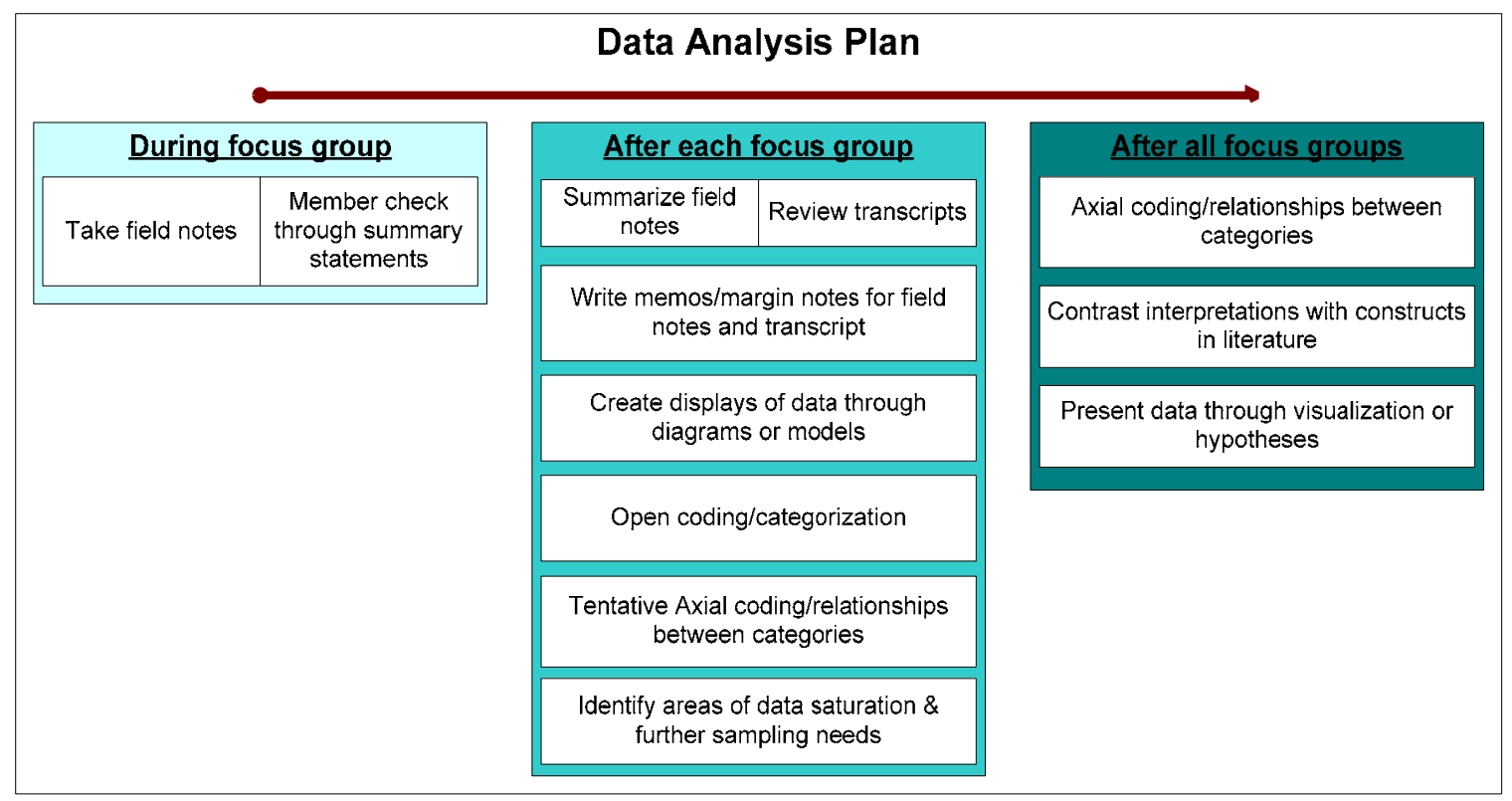

Figure 3: Data analysis plan

\section{Dissemination of Results}

Findings will be disseminated through national conference presentations or peerreviewed journal articles. Individual respondents will not be identified in any reports. Findings from this study can inform the practice of technology designers, policy makers and health care providers.

\section{Human Subjects}

Potential participants were contacted by bulletin board flyer or letter, which explained the nature of the study and provided them with consent information. In 
addition to the contact letters, a brief review of research participant rights was listed at the beginning of the focus group. Written material regarding the rights of study participants (informed consent material) was available to participants, who wished to have it. Contact information for the principal investigator was given to all participants. Attendance at the focus group was considered to be consent to participate in the study.

Respondents were not compensated for their participation. Participants could have elected to receive a summary of the research findings by either emailing or calling the principal investigator.

Children, pregnant women and incarcerated individuals were not included as participants in this study as this study was focused on older adults ages 65 and older living in residential care facilities. Residents of both genders were invited to participate in focus group sessions. If respondents had seemed inhibited during mixed gender groups, additional single gender focus groups would have been recruited.

Confidentiality was the largest concern for human subjects in this study and as such a waiver of written documentation of informed consent was sought. All transcription and original audio recordings were stored in a locked research office accessible only to the research team. All names were removed from the transcripts. At the end of the study, all links between study participant number and participant identity and original audio recordings will be destroyed. No information released from this study will include identifiable information.

Additionally as this method used focus groups, the confidentiality of participants' responses was also a shared responsibility of all the group participants. The group nature of the study and the potential risk for loss of confidentiality was explained to all potential 
participants prior to their participation. Furthermore, the group facilitator reviewed the principle of group confidentiality before beginning the discussion. Prior focus group research had shown that despite researcher concerns for group confidentiality, participants had felt comfortable sharing sensitive experiences and participating in focus group discussions (Morse, 1994). 


\section{References}

Altman, I. (1975). Privacy mechanisms and functions. In The Environment and Social Behavior: Privacy, Personal Space, Territory, Crowding (pp. 32-51). Monterey, CA: Brooks/Cole Publishing.

Altman, I. (1975). Privacy: Definitions and properties. In The Environment and Social Behavior: Privacy, Personal Space, Territory, Crowding (pp. 10-31). Monterey, CA: Brooks/Cole Publishing.

Angus, J., Kontos, P., Dyck, I., McKeever, P., \& Poland, B. (2005). The personal significance of home: Habitus and the experience of receiving long-term home care. Sociology of Health \& Illness, 27(2), 161-187.

Archea, J. (1977). The place of architectural factors in behavioral theories of privacy. Journal of Social Issues, 33(3), 116-137.

Bauer, K. A. (2001). Home-based telemedicine: A survey of ethical issues. Cambridge Quarterly of Healthcare Ethics, 10, 137-146.

Benoliel, J. W. (1996). Grounded theory and nursing knowledge. Qualitative Health Research, 6, 406-428.

California HealthCare Foundation. (1999). Medical privacy and confidentiality survey summary and overview. Retrieved 10/3/2005, from www.chcf.org/publications

Carey, M. A. (1994). The group effect in focus groups: Planning, implementing, and interpreting focus group research. In J. Morse (Ed.), Critical Issues in Qualitative Research Methods (pp. 225-241). Thousand Oaks, CA: Sage Publications. 
Centers for Medicare and Medicaid Services. (2002). Health Insurance Portability and Accountability Act of 1996 (HIPAA). Retrieved 10/14/2002, from http://www.cms.hhs.gov/hipaa/default.asp

Cowan, D., \& Turner-Smith, A. (1999). The role of assistive technology in alternative models of care for older people. In With Respect to Old Age - Research Volume 2 (pp. 325-346). London.

Creswell, J. W. (1998). Qualitative Inquiry and Research Design: Choosing Among Five Traditions. Thousand Oaks, CA: Sage Publications.

Da Silva, B. (2002). Young homeless women encountered physical and individual barriers in obtaining health care. Evidence-Based Nursing, 5(4), 124.

Demiris, G., Rantz, M. J., Aud, M. A., Marek, K. D., Tyrer, H. W., Skubic, M., et al. (2004). Older adults' attitudes towards and perceptions of "smart home" technologies: A pilot study. Medical Informatics \& The Internet in Medicine, 29(2), 87-94.

Deshefy-Longhi, T., Dixon, J. K., Olsen, D., \& Grey, M. (2004). Privacy and confidentiality issues in primary care: Views of advanced practice nurses and their patients. Nursing Ethics, 11(4), 378-393.

de Veer, A. J. E., \& Kerkstra, A. (2001). Feeling at home in nursing homes. Journal of Advanced Nursing, 35(3), 427-434. 
Dewsbury, G., Sommerville, I., Rouncefield, M., \& Clarke, K. (2002). Bringing IT into the home. Retrieved 09/09/2005, from http://www.comp.lancs.ac.uk/computing/research/cseg/projects/dirc/index.htm

Dewsbury, G., Taylor, B., \& Edge, M. (2001). The process of designing appropriate smart homes: Including the user in the design. Paper presented at the Equator IRC Workshop on Ubiquitous Computing in Domestic Environments, University of Nottingham, UK.

Ellefsen, B. (2002). Dependency as a disadvantage - patients' experiences. Scandinavian Journal of Caring Science, 16, 157-164.

Garside, R., Ayres, R., Owen, M., Pearson, V. A. H., \& Roizen, J. (2002). Anonymity and confidentiality: rural teenagers' concerns when accessing sexual health services. Journal of Family Planning \& Reproductive Health Care, 28(1), 23-26.

Goldman, J., \& Hudson, Z. (1999). Promoting health protecting privacy: A primer. Retrieved 10/3/2005, from www.chcf.org/publications

Goldman, J., \& Hudson, Z. (2000). Virtually exposed: Privacy and E-health. Health Affairs, 19(6), 140-148.

Goodwin, L. K., Courtney, K. L., Kirby, J. D., Iannachione, M. A., \& Manley, T. (2002). A Pilot Study: Patients' Perceptions About the Privacy of Their Medical Records Online Journal of Nursing Informatics, 6(3). 
Goold, S. D., \& Klipp, G. (2002). Managed care members talk about trust. Social Science \& Medicine, 54(6), 879-888.Hughes, M. (2004). Privacy in aged care. Australasian Journal on Ageing, 23(3), 110-114.

Hawes, C., Phillips, C. D., Holan, S., Sherman, M., \& Hutchinson, L. L. (2005). Assisted living in rural America: Results from a national survey. Journal of Rural Health, 21(2), 131-139.

Health Resources and Services Administration. (2002). Projected Supply, Demand, and Shortages of Registered Nurses: 2000-2020: U.S. Department of Health and Human Services.

Hughes, M. (2004). Privacy in aged care. Australasian Journal on Ageing, 23(3), 110114.

Krueger, R.A. (1998). Developing Questions for Focus Groups. Thousand Oaks, CA: Sage Publications.

Krueger, R. A. (1998b). Analyzing \& Reporting Focus Group Results. Thousand Oaks, CA: Sage Publications.

Krueger, R. A., \& Casey, M. A. (2000). Focus Groups: A Practical Guide for Applied Research (3rd ed.). Thousand Oaks, CA: Sage Publications.

Leino-Kilpi, H., Valimaki, M., Dassen, T., Gasull, M., Lemonidou, C., Scott, A., et al. (2001). Privacy: A review of the literature. International Journal of Nursing Studies, 38(6), 663-671. 
Lemonidou, C., Leino-Kilpi, H., Valimaki, M., Dassen, T., Gasull, M., Scott, P. A., et al. (2003). Privacy in surgical nursing care: a comparative study of patients' and nurses' perceptions. Journal of Advanced Perioperative Care, 1(4), 113-122.

Lemonidou, C., Merkouris, A., Leino-Kilpi, H., Valimaki, M., Dassen, T., Gasull, M., et al. (2002). Nurses' and elderly patients' perceptions regarding autonomy, privacy and informed consent in nursing interventions in Greece. Reviews in Clinical Gerontology, 12(3), 191-204.

Lester, T. (March 2001). The reinvention of privacy. Atlantic Monthly, 27-39.

Lichtenstein, B. (2003). Stigma as a barrier to treatment of sexually transmitted infection in the American deep south: issues of race, gender and poverty. Social Science \& Medicine, 57(12), 2435-2445.

Lumpkin, J. R. (2000). E-Health, HIPAA and beyond. Health Affairs, 19(6), 149-151.

Malcolm, H. A. (2005). Does privacy matter? Former patients discuss their perceptions of privacy in shared hospital rooms. Nursing Ethics, 12(2), 156-166.

Mangusson, L., \& Hanson, E. (2003). Ethical issues arising from a research, technology and development project to support frail older people and their family carers at home. Health and Social Care in the Community, 11(5), 431-439.

Mangusson, L., \& Hanson, E. (2005). Supporting frail older people and their family carers at home using information and communication technology: Cost analysis. Journal of Advanced Nursing, 51(6), 645-657. 
Marek, K. D., Popejoy, L., Petroski, G., Mehr, D., Rantz, M. J., \& Wen-Chieh, L. (2005). Clinical outcomes of Aging in Place. Nursing Research, 54(3), 202-211.

Marek, K. D., \& Rantz, M. J. (2000). Aging in Place: A new model for long-term care. Nursing Adminstration Quarterly, 24(3), 1-11.

Marek, K. D., Rantz, M. J., \& Porter, R. T. (2004). Senior Care: Making a difference in long-term care of older adults. Journal of Nursing Education, 43(2), 81-83.

Miskelly, F. G. (2001). Assistive technology in elderly care. Age and Aging, 30, 455-458.

Monshi, B., \& Zieglmayer, V. (2004). The problem of privacy in transcultural research: Reflections on an ethnographic study in Sri Lanka. Ethics \& Behavior, 14(3), 305-312.

Morgan, D. (1992). Doctor-caregiver relationships. In B. Crabtree \& W. Miller (Eds.), Doing qualitative research (1 ed., pp. 205-227). Newbury Park, CA: Sage.

Morse, J. M. (Ed.). (1994). Critical issues in qualitative research methods. Thousand Oaks, CA: Sage.

Phillips, C. D., Holan, S., Sherman, M., Spector, W., \& Hawes, C. (2005). Medicare expenditures for residents in assisted living: Date from a national study. HSR: Health Services Research, 40(2), 373-388.

Randers, I., \& Mattiasson, A.-C. (2000). The experiences of elderly people in geriatric care with special reference to integrity. Nursing Ethics, 7(6), 503-519. 
Rantz, M. J., Marek, K. D., Aud, M. A., Johnson, R. A., Otto, D., \& Porter, R. (2005). Tiger Place: A new future for older adults. Journal of Nursing Care Quality, 20(1), 1-4.

Rantz, M. J., Marek, K. D., Aud, M. A., Tyrer, H. W., Skubic, M., Demiris, G., et al. (2005). A technology and nursing collaboration to help older adults age in place. Nursing Outlook, 53, 40-45.

Rantz, M. J., Marek, K. D., \& Zwygart-Stauffacher, M. (2000). The future of long-term care for the chronically ill. Nursing Adminstration Quarterly, 25(1), 51-58.

Ray-Degges, S. (1995). Privacy: The experiences of thirteen nursing home residents. Unpublished Dissertation, University of Missouri - Columbia, Columbia, MO.

Rialle, V., Duchene, F., Noury, N., Bajolle, L., \& Demongeot, J. (2002). Health "Smart" home: Information technology for patients at home. Telemedicine Journal and eHealth, 8(4), 395-409.

Rogers, E. (1995). Diffusion of Innovations (4th ed.). New York: The Free Press.

Roosa, W. M. (1982). Territory and privacy Residents' views: Findings of a survey. Geriatric Nursing, 3, 241-243.

Rousch, C. V., \& Cox, J. E. (2000). The meaning of home: How it shapes the practice of home and hospice care. Home Healthcare Nurse, 18(6), 388-394.

Sandelowski, M. (1995). Sample size in qualitative research. Research in Nursing and Health, 18, 179-183. 
Sandelowski, M. (2000). Whatever happened to qualitative description? Research in Nursing and Health, 23, 334-340.

Schopp, A., Leino-Kilpi, H., Valimaki, M., Dassen, T., Gasull, M., Lemonidou, C., et al. (2003). Perceptions of privacy in the care of elderly people in five European countries. Nursing Ethics, 10(1), 39-47.

Scott, P. A., Valimaki, M., Leino-Kilpi, H., Dassen, T., Gasull, M., Lemonidou, C., et al. (2003). Autonomy, privacy and informed consent 1: Concepts and definitions. British Journal of Nursing, 12(1), 43-47.

Smith, M. W. (1995). Ethics in focus groups: A few concerns. Qualitative Health Research, 5, 478-486.

Spitzer, W. J., Neuman, K., \& Holden, G. (2004). The coming of age for assisted living care: New options for senior housing and social work practice. Social Work in Health Care, 38(3), 21-45.

Stanfield, R. B. (2000). The art of focused conversation: 100 ways to access group wisdom in the workplace (2nd ed.). Toronto, ON: The Canadian Institute of Cultural Affairs.

Stefanov, D. H., Zeungnam, B., \& Bang, W.-C. (2004). The smart house for older persons and persons with physical disabilities: Structure, technology arrangements and perspectives. IEEE Transactions on Neural Systems and Rehabilitation Engineering, 12(2), 228-250. 
Straw, R. B., \& Smith, M. K. (1995). Potential uses of focus groups in federal policy and evaluation studies. Qualitative Health Research, 5, 421-427.

Suzuki, R., Ogawa, M., Otake, S., Izutsu, T., Tobimatsu, Y., Izumi, S.-I., et al. (2004). Analysis of activities of daily living in elderly people living alone: Single-subject feasibility study. Telemedicine Journal and e-Health, 10(2), 260-276.

Tamm, M. (1999). What does a home mean and when does it cease to be a home? Home as a setting for rehabilitation and care. Disability and Rehabilitation, 21(2), 49-55.

Westin, A. (1970). Privacy and Freedom. New York, NY: Atheneum.

White, G. E., \& Thomson, A. N. (1995). Anonymized focus groups as a research tool for health professionals. Qualitative Health Research, 5, 256-261.

Williams, A. (2002). Changing geographies of care: Employing the concept of therapeutic landscapes as a framework in examining home space. Social Science \& Medicine, 55(1), 141-154.

Williams, A. (2004). Shaping the practice of home care: Critical case studies of the significance of the meaning of home. International Journal of Palliative Nursing, 10(7), 333-342.

Wilson, K. B. (1996). What is assisted living? Journal of Long Term Care Administration, 24(3), 3-4. 
Appendix A

\section{Privacy and Adoption of Assistive Technology in Residential Care Facilities Focus Group Interview Guide}

Background information:

Several types of assistive technologies will be described and displayed to participants during the focus group session beginning with question 7. These technologies may include: gait monitors, motion sensors, kitchen sensors, bed, chair or floor sensors and sensor equipment with video/picture capabilities.

Focus group session:

At the beginning of the focus group the group facilitator will introduce himself/herself, review the consent to participate in the study and the principles of group confidentiality. The group facilitator will ask the participants to give their first name and how long they have been a resident.

1. How do you define privacy?

a. Potential cue - what do you consider private here? (information, interactions with others, the ability to be yourself, etc?)

2. What are some of the most important elements of your personal sense of privacy?

a. Potential cue - what types of things or events take away your sense of privacy? What types of things or events strengthen your sense of privacy?

3. What are your initial thoughts about privacy within a residential care living facility such as the one you live in?

a. Potential cue - what is the first thought that comes to mind when you think about privacy here as opposed to other types of living arrangements?

4. Please describe some situations within this living environment that might make you worry about your privacy?

a. Potential cue - Have you had anything happen that you considered a violation of your privacy? This could include things about your personal information, your interactions with other people here, the ability to be yourself, etc)

5. What types of things might you do to protect your privacy while living here?

a. Potential cue - Have you done changed your routines or the arrangement of your apartment? Have you maybe held information back from people or only told them part of the story?

6. Assistive technologies are information-based technologies that collect and share health information with health care providers such as nurses or physicians. Some types of assistive technologies that are being developed for residential care settings include: emergency help, falls detection, physiological monitoring, cognitive reminder systems and medication management. What are your initial thoughts about using assistive technologies?

a. Potential cue - what do you think about when you hear about technology such as a device to detect whether or not a person has fallen in their apartment? 
7. Please describe situations in which [insert assistive technology name] could be beneficial to you or others?

a. Potential cue - Motion sensors could count how many times you've entered a room, say a bathroom at night for example - can you think times when gathering information like this could be helpful to you or to other people? What about other sensors and the information they might gather?

8. Please describe situations in which [insert assistive technology name] could be would not be helpful to you?

a. Potential cue - For example, stove top sensors are designed to detect when a stove burner has been left on accidentally. Some residents do not use their stoves and have unplugged them. For those seniors, stove top sensors are probably not so helpful. What about in your situation?

9. What types of concerns would you have about having [insert assistive technology name] in your room?

a. Potential cue - For example, some residents have expressed a concern about tripping over floor sensor mats? Would this be something you would worry about?

10. What are your initial thoughts about privacy and some of the assistive technologies shown here today?

a. Potential cue - Would any of these devices change your sense of privacy?

11. Please describe a situation in which you would not use an assistive technology device because of privacy concerns?

a. Potential cue - Some seniors in earlier studies have had concerns about using emergency call button necklaces because they felt that wearing these devices would share information about their health status with anyone who saw them. Can you think of situations with the technologies here that might raise similar concerns?

12. Please describe a situation in which you would use an assistive technology device despite privacy concerns?

a. Potential cue - For example, having a medication dispenser on the kitchen counter may alert visitors that you are taking medications, but you may feel the convenience of using the machine to take your medications on time outweighs your privacy concerns. What types of technological assistance would be more important than your privacy concerns?

13. Are some assistive technologies more of a privacy concern than others?

a. Potential cue - We've shown a number of assistive technologies today. Some which capture your image, such as the video-cameras, your health information, such as the bed sensor or information on your surroundings such as the stove top sensor. Does the type of technology or the information gathered change your privacy concerns?

14. How important is privacy in making decisions about using assistive technologies here?

a. Potential cue - Would your concerns about privacy be the deciding factor in whether or not you were to use a particular technology? 
15. We have talked a lot today about privacy and assistive technology. Is there anything we have not covered that you would like to add to our conversation?

Following the discussion, the facilitator will summarize the main points from the discussion and thank the residents for their participation. 
Institutional Review Board Health Sciences Section

University of Missouri-Columbia
125 Folk Hall

One Hospital Drive

Columbia, MO 65212

PHONE (573) 882-3181

FAX (573) 884-4401

E-MAIL: irb@missouri.edu

WEB: www.research.missouri.edu/hsirb

January 13, 2006

Karen Courtney, MD

Health Management \& Informatics

324 Clark Hall

Columbia, MO 65212

Dear Dr. Courtney,

Regarding your application for approval of the research project, Privacy and Adoption of Assistive Technology in Residential Care Facilities, the Health Sciences Institutional Review Board (HS IRB) took the following action:

a. Approved your application through expedited review [as codified under 45 CFR 46.110 (f) (6 \& 7)] on January 5, 2006.

b. Found this protocol to impose minimal risk to the research participant.

c. The HS IRB has waived the requirement for the investigator to obtain a signed consent form for all research participants in accondance with 45 CFR 46.116 (d). Although the requirement to obtain a signature has been waived, a copy of the consent script that was approved on January 12, 2006 must be given to each research participant to keep for his or her records.

d. Reviewed and approved any advertisements or other recruitment materials that were submitted with your application.

e. Found that there is no HIPAA requirement for this project.

f. The HS IRB has determined that the degree of risk is such that the approval for this protocol will expire on January 5, 2007. A Continuing Review Report must be submitted a minimum of one month prior to this date.

Please reference IRB Project \# 1058581 in all future communications regarding this project.

Before enrolling patients at the Truman V.A. Hospital, all research involving human participants must be approved by both the appropriate MU IRB and the V.A. Research and Development Committee. This requirement includes Principal Investigators who are V.A. employees conducting research outside of the V.A., and any non-V.A. employees who are either recruiting V.A. patients or using V.A. facilities for their research. If you meet any of the above criteria, please contact Karen Watson in the V.A. Research Office at 814-6550.

Pursuant to the HS IRB conflict of interest policy, investigators who are HS IRB members do not vote on protocols in which they are involved.

Death occurring in a study at this site must be reported to the HS IRB office within 24 hours of occurrence, whether or not the death is related to the study. All on-site serious adverse events must be reported to the HS IRB office within five (5) days of occurrence.

No change may be made in an approved protocol or recruitment materials unless the change is submitted to and approved by the HS IRB.

Do not depend on the HS IRB for your record keeping. Pursuant to federal regulations, the IRB retains files of only three years after termination of a research project.

Sincerely,

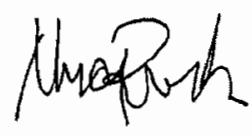

Niels Beck, $\mathrm{PhD}$

Chair

Enclosure 
PART II - RESEARCH RESULTS 


\title{
PRIVACY AND SENIOR ADOPTION OF ASSISTIVE TECHNOLOGY IN RESIDENTIAL CARE
}

\author{
Karen L. Courtney, RN, MSN \\ University of Missouri - Columbia \\ 324 Clark Hall \\ Columbia, MO 65211 \\ (573) 424-0880
}

Karen.Courtney@alumni.duke.edu

\section{Acknowledgements:}

This work was supported in part by the National Library of Medicine Biomedical and Health Informatics Research Training Grant T15-LM07089-14, Alpha Iota Chapter of Sigma Theta Tau, International and the Center for e-Research at the University of Missouri - Columbia. 


\begin{abstract}
Within the next twenty years, there is a large increase anticipated in the segment of the population ages sixty five and older and a subsequent increase in demand on residential care facilities. With this expectation, researchers have been exploring the use of assistive information-based technologies in residential care facilities to enhance resident quality of life and safety. Assistive technologies in this context are information-based technologies that collect and share resident information to health care providers such as nurses or physicians. Little evaluation research exists on user acceptance and effectiveness of assistive technologies in RC facilities (Demiris et al., 2004). Older adults' perceptions of privacy can inhibit their adoption of assistive technologies. This qualitative study used descriptive content analysis of focus group sessions and individual interviews to explore the relationship between privacy, living environment and willingness to adopt assistive technology with older adults living in residential care facilities. The findings from this study indicate that privacy can be a barrier for older adults' adoption of assistive technologies; however their perception of their need for the technology may override their own privacy concerns. Privacy concerns, as a barrier to technology adoption, can be influenced by both individual-level and community-level factors. Further exploration of the factors influencing older adults' perceptions of assistive technology need is necessary.
\end{abstract}

Keywords: Medical Informatics, Telemedicine, Smart Home Technology, Aged, Frail Elderly, Residential Facilities 


\section{Introduction}

The segment of the population that is 65 years and older is expected to grow $54 \%$ between 2000 and 2020 and place additional demand on residential care (RC) facilities (HRSA, 2002). With the growth in the older adult population residing in RC facilities, these facilities are increasingly adopting assistive information-based technologies for the well-being of their residents. Assistive technologies in this context are information-based technologies that collect and share resident information to health care providers such as nurses or physicians. The purpose of assistive technologies are to help individuals with tasks they would otherwise be unable to do or to help individuals perform a given task more easily or safely (Cowan \& Turner-Smith, 1999; Dewsbury, Taylor \& Edge, 2001). Types of assistive technologies that are being developed include: emergency help, falls detection, physiological monitoring, cognitive reminder systems and medication management (Demiris et al., 2004). Little evaluation research exists on user acceptance and effectiveness of assistive technologies in RC facilities (Demiris et al., 2004).

Older adults' perceptions of privacy can inhibit their adoption of assistive technologies that could enhance quality of life and increase home safety. Health care providers and researchers cannot assume that health care consumers will necessarily reduce their expectations of privacy based on potential health benefits. In a national survey, $60 \%$ of adults surveyed indicated they would not grant access to their health information in order to participate in a preventive care program (California HealthCare Foundation, 1999). This finding suggests that perceived benefit alone may not mitigate privacy needs or expectations. 
Privacy research typically has focused primarily on inpatient, hospital experiences rather than outpatient experiences within the community (Leino-Kilpi et al., 2001). This is particularly true for older adults over age 65 . Additional research is needed to understand the privacy perceptions of older adults residing in licensed residential care facilities, such as assisted living, innovative intermediate care or skilled nursing facilities (Hughes, 2004).

Additionally, the relationship between the meaning of privacy for this population of older adults and their acceptance of assistive technologies has not been well investigated. Preliminary research has noted associations between lower levels of independence and less positive perceptions of privacy in long term care settings (Schopp et al., 2003). It is not known if assistive technologies would mitigate or exacerbate this association. Potentially, if the privacy behaviors of this group are similar to other adults, these concerns could lead to: underutilization of both health care providers and assistive technologies, increased barriers in diffusion (Rogers, 1995) of assistive technologies and ineffectiveness of interventions that are based on these technologies. A better understanding of the meaning of privacy and its relationship to assistive technology adoption by older adults in residential care facilities is needed to inform the design of appropriate interventions to increase adoption of such technologies.

The research question for this study was: "How does the meaning and perceptions of privacy by older adults living in residential care facilities affect their willingness to adopt assistive information technologies?" This study used a descriptive, qualitative approach with focus groups and individual interviews to address the following aims: 
1. To explore the meaning of privacy to older adults (ages 65 and above) in residential care facilities

2. To examine how this meaning of privacy affects the willingness of older adults to adopt assistive technologies.

\section{Background}

The relationships between privacy, living environment and assistive technologies were explored in this study. The concepts of privacy and living environment have been linked within the literature as have the concepts of living environments and assistive technologies. Little prior research however had explored the connections between privacy and assistive technologies within different living environments (Bauer, 2001).

\section{Privacy}

Despite many references in the literature, privacy is a multidimensional concept lacking a universal definition (Lemonidou et al., 2002; Scott et al., 2003). The terms privacy and confidentiality are often used incorrectly as interchangeable terms by health care providers and occasionally within the literature (Goodwin, Courtney, Kirby, Iannacchione \& Manley, 2002). As an example of the distinction between privacy and confidentiality in health information, privacy refers "to an individual's desire to control access" and confidentiality refers to "the obligation of a holder of identifiable personal health information to protect the person's privacy" (Lumpkin, 2000, p. 149). This study is concerned with an individual's desire and ability to control access to self (privacy) rather than mechanisms designed to respect an individual's privacy expectations (confidentiality). 
The concept of privacy has been described or categorized in several different ways pertaining to: function (Westin, 1970), type (Westin, 1970; Leino-Kilpi et al., 2001), practices (Leino-Kilpi et al., 2001; Monshi \& Zieglmayer, 2004) and dimension (Leino-Kilpi et al, 2001). Despite a lack of a universal definition for privacy as a concept, there are several descriptive dimensions of privacy which are consistent within the literature.

Privacy Dimensions

Conceptually, privacy concerns are often seen in four distinct dimensions: psychological, social, physical and informational (Leino-Kilpi et al., 2001). Each of these dimensions of privacy can result in different privacy responses to situations. Explanations of each privacy dimension from the literature are included in Table 1.

Table 1: Dimensions of Privacy

\begin{tabular}{|l|l|}
\hline $\begin{array}{l}\text { Privacy } \\
\text { Dimension }\end{array}$ & Explanation \\
\hline Psychological & $\begin{array}{l}\text { Refers to the maintenance of a personal identity through individual } \\
\text { control of cognitive and affective behavior (Hughes, 2004; Leino-Kilpi } \\
\text { et al., 2001). }\end{array}$ \\
\hline Social & $\begin{array}{l}\text { Refers to the individual's control over their social contacts (Leino-Kilpi } \\
\text { et al., 2001). }\end{array}$ \\
\hline Physical & $\begin{array}{l}\text { Refers to the individual's control of physical access to oneself (Leino- } \\
\text { Kilpi et al., 2001). Physical access can also include the personal space or } \\
\text { territory of an individual (Leino-Kilpi et al., 2001). }\end{array}$ \\
\hline Informational & $\begin{array}{l}\text { Refers to the individual's control over the collection and distribution of } \\
\text { personal information (Hughes, 2004; Leino-Kilpi et al., 2001). }\end{array}$ \\
\hline
\end{tabular}

Psychological privacy.

The psychological dimension of privacy refers to the maintenance of a personal identity through individual control of cognitive and affective behavior (Hughes, 2004; Leino-Kilpi et al., 2001). The concepts of psychological privacy and identity have been linked within the literature (Altman, 1975). Psychological privacy is often presented as a 
condition for individual growth and development (Leino-Kilpi et al., 2001).

Psychological privacy is tied to self-observation and self-identity (Altman). "But it is not the inclusion or exclusion of others that is vital to self-definition; it is the ability to regulate contact when desired." (Altman, p. 50) Violation of psychological privacy can be a serious loss of individual control in addition to the unintended release of information (Altman).

\section{Social privacy.}

Social privacy refers to the individual's control over their social contacts (LeinoKilpi et al., 2001). Social privacy can be seen in Westin's states of privacy which describe the interactions with various sizes of groups (Leino-Kilpi et al.). Hughes (2004) noted that living environments can enhance or detract from an individual's sense of social privacy. "In communal environments older consumers have little influence over who they have contact with and inevitably not all interaction is likely to be pleasant." (Hughes, 2004, p. 112)

\section{Physical privacy.}

Physical privacy refers to the individual's control of physical access to oneself (Leino-Kilpi et al., 2001). Physical access can also include the personal space or territory of an individual (Leino-Kilpi et al.). Leino-Kilpi et al. suggested that physical privacy can be tied to Westin's privacy function of "emotional release".

In Ray-Degges' (1995) study of nursing home residents, she found that the type of room or living environment influenced resident's definitions of privacy. In this study, residents with private rooms were more likely to define privacy as solitude or physical aloneness; however residents with semi-private rooms defined privacy as controlling 
access to oneself. Residents in both room types described manipulating the physical arrangements of the room (furniture, curtains, etc) to enhance their privacy (RayDegges). Archea (1977, p. 121) suggests that "the arrangement of the physical environment" influences personal behavior and perceptions of privacy through the distribution of visual information. Likewise it has been suggested that the physical space and structure of the home environment facilitate privacy (Angus, Kontos, Dyck, McKeever \& Poland, 2005).

Physical privacy has also been linked to issues of personal space and territoriality (Randers \& Mattiasson, 2000; Tamm, 1999). In interviews with older adults within an in-patient facility, personal property and the immediate personal space emerged as extensions of the older adult's identity (Randers \& Mattiasson, 2000). The respondents perceived the unannounced entrance of others into their personal space and the uninvited handling of personal items to be privacy or integrity violations (Randers \& Mattiasson). Likewise in a survey of nursing home residents $(\mathrm{n}=56)$, Roosa $(1982)$ noted that areas surrounding a resident's bed were considered to be "owned" by the resident. Residents expressed that their privacy had been violated when owned areas were used or examined by others (Roosa).

Informational privacy.

Informational privacy is the individual's control over the collection and distribution of personal information (Hughes, 2004). Within the last decade, concerns about informational privacy and confidentiality have become more prominent within both scholarly and public discourse. In the United States, the implementation of privacy and security regulations associated with the Health Insurance Portability and Accountability 
Act of 1996 PL 104-191 (HIPAA) has prompted greater consumer, researcher and health care provider interest in informational privacy and confidentiality (Centers for Medicare and Medicaid Services, 2003).

Additionally, it has been suggested that obtaining information about a person against their will also constitutes a violation of informational privacy (Leino-Kilpi et al., 2001). Potentially, this aspect of informational privacy could play a role in an individual's view of information-based assistive technologies which collect and share information, such as one's activity levels, sleeping patterns or treatment adherence, with health care providers.

These different dimensions of privacy can lead to different individual privacy needs. Furthermore, different situations can stimulate privacy needs based on one or more of the dimensions of privacy. An example of the complex interaction of different dimensions of privacy within one situation is Bauer's (2001) discussion of how homebased, telemedicine applications can simultaneously enhance physical privacy and increase the risk of informational privacy violations. In his discussion, he notes that the use of telemedicine applications could decrease the physical intrusion of health care providers into the home setting while also introducing the risk of privacy violation through inappropriate or unintentional information sharing through the information technology used (Bauer).

\section{Consequences of Perceived Privacy Loss}

However, even prior to HIPAA implementation, patient privacy concerns were well documented. In 2001, Lester reported that only $12 \%$ of patients were unconcerned about their privacy and uses of their personal health information (PHI). Furthermore, 
health care consumers are viewing technological advances in record keeping with skepticism. As early as 1997, former Secretary of Health and Human Services Shalala noted that nearly $75 \%$ of citizens are at least somewhat concerned about how computerization of their health records will negatively affect their privacy (Shalala, 1997). In a study of ambulatory care patients and parents of pediatric patients $(n=92)$, $80 \%$ of respondents indicated they cared "a lot" about their information privacy (Goodwin et al., 2002).

Despite consumer concern over potential health information privacy violations, in a national survey $(\mathrm{n}=1000)$ only a small number of health care consumers $(18 \%)$ believe they personally have had their health information privacy violated (California HealthCare Foundation, 1999). Of this group, however, nearly half said the violation caused personal embarrassment or harm (California HealthCare Foundation). Health care consumers are worried not only that their privacy will be violated but also that "their health information will be used to hurt them" (Goldman \& Hudson, 2000, p. 140).

Patient's concerns over health information privacy have demonstrable, detrimental effects on their interactions with health care providers. Goold and Klipp (2002) suggested patient mistrust can lead to the withholding of information or the disclosure of misleading information to their health care providers. Similarly, another survey noted that one in six persons is "privacy protective" in their health care interactions (California HealthCare Foundation, 1999). These "privacy protective" behaviors include: giving incomplete or inaccurate information; asking providers not to record certain pieces of information; frequent health care provider changes; avoidance of the health care system; and paying out of pocket for health services (California 
HealthCare Foundation). Consumers, who believe their health information privacy has been violated, were four times more likely to engage in privacy protective behaviors than those who do not believe their information privacy has been violated (California HealthCare Foundation).

Prior research with focus groups has confirmed these privacy protective behaviors in adult primary care patients (Deshefy-Longhi, Dixon, Olsen \& Grey, 2004). In this study, patients shared that they had made requests for not documenting conversations due to privacy concerns and they indicated a strong desire to control access to their information (Deshefy-Longhi et al., 2004). Likewise privacy protective behaviors were observed in Malcolm's (2005) study of adults in shared rooms within an inpatient facility. The situation-dependent privacy perceptions of respondents influenced whether or not they would limit or withhold information with their health care providers (Malcolm). Assurance of quality and access to health care for individuals and communities are dependent on privacy protection (Goldman \& Hudson, 1999).

\section{Living Environment}

Home

Williams (2002) argued that the meaning of place is a key to understanding the importance of that place. The concept of home has been linked to privacy as a specific location where privacy and identity are protected (Rousch \& Cox, 2000; Tamm, 1999; Williams, 2004). Additionally, the concept of home includes the home as a familiar place of comfort and the home as the center of everyday experiences (Rousch \& Cox, 2000; Tamm, 1999; Williams, 2004). All three of these dimensions of home are linked to familiar routines, physical arrangements and the social structure of the home (Rousch \& 
Cox). Often residents idealize their personal concept of home (Rousch \& Cox). The actual experience of home may be considerably different than residents' ideal home especially as personal health conditions change (Rousch \& Cox).

The inclusion of health services within the home environment can influence changes in residents' beliefs, experiences and meaning of home (Angus et al., 2005; Ellefsen, 2002; Tamm, 1999; Williams, 2002). Therefore when the home is within a residential care facility, the beliefs, experiences and meanings associated with personal identity and privacy may also be affected.

\section{Residential Care and Assisted Living}

Within this study residential care facilities included both a traditional, licensed assisted living care facility and an innovative, residential care facility, using an Aging in Place model of care that is licensed as an intermediate care facility. The later residential care facility was made possible by the Missouri legislature through waivers and its designation as an Aging in Place demonstration site (Rantz, Marek, Aud, Johnson et al, 2005). Both facilities contain only private apartment homes rather than shared rooms. Throughout this paper, the term residential care (RC) facility will be used as a broader, inclusive term for both types of residential care settings.

Residential care facilities aim to provide personal and health-related services within a homelike environment (Wilson, 1996). The goals of RC facilities typically include a commitment to maximizing resident "dignity, privacy, independence and autonomy" (Wilson, p. 3). Residents within RC facilities are generally considered to be dwelling in the community rather than in an institution (skilled nursing or long-term care 
facilities) (Hawes, Phillips, Holan, Sherman \& Hutchinson, 2005; Phillips, Holan, Sherman, Spector \& Hawes, 2005; Wilson, 1996)

Although a goal of RC facilities may be to enhance resident independence, autonomy, privacy and safety, typically facilities will transfer residents to a different facility when their health care needs increase (Marek \& Rantz, 2000; Rantz, Marek, Aud, Johnson et al., 2005). This transition to skilled nursing facilities or nursing homes has been associated with resident's health decline (Marek \& Rantz, 2000). Community dwelling residents can be fearful of forced relocation to nursing homes (Rantz, Marek, Aud, Johnson et al., 2005).

\section{Aging in Place Model.}

In response to concerns about changes in older adults' health status and fears regarding relocation, a newer model of care delivery is being emphasized within RC facilities, “Aging in Place” (Marek \& Rantz, 2000; Marek, Rantz \& Porter, 2004; Rantz, Marek, Aud, Johnson et al., 2005; Rantz, Marek, Aud, Tyrer et al., 2005). In contrast to traditional models of care, RC facilities using an "Aging in Place" model emphasize the care coordination of services to allow senior residents to stay in their chosen homes even as their health care needs change over time (Marek \& Rantz, 2000; Rantz, Marek \& Zwygart-Stauffacher, 2000).

The goals of an Aging in Place model in RC facilities are to "help older people stay healthier and active longer, avoid expensive and debilitating hospitalizations and for most residents, avoid relocation to a nursing home" (Rantz, Marek, Aud, Tyrer et al., 2005, p.41). Use of the Aging in Place model with a community dwelling seniors ( $\mathrm{n}=$ 156), demonstrated significantly better clinical outcomes (cognition, depression, 
activities of daily living and incontinence) for community-based seniors receiving Aging in Place services $(n=78)$ versus a matched set of nursing home residents $(n=78)$ who were not receiving Aging in Place services (Marek, Popejoy, et al., 2005).

\section{Effects on privacy.}

The living environment of a RC facility affects residents' privacy needs through a variety of dimensions. RC facilities are designed to provide "home-like" residential environments (Spitzer, Neuman \& Holden, 2004; Wilson, 1996). "Resident care in assisted living more frequently evolves from a residential rather than medical model." (Spitzer et al., 2004, p. 27) In a study of 686 nursing home residents, residents' perceptions of "feeling at home" were related to their perceptions of privacy (deVeer \& Kerkstra, 2001). Hughes (2004) suggested that the "home" is part of personal identity and as such a transition to a residential care facility can represent a challenge to one's sense of psychological privacy as well as physical and informational privacy.

Tamm (1999) noted that re-arrangement of furniture by others or introduction of technological aids into the home environment can be a significant intrusion and affect an individual's sense of identity and privacy. This finding is consistent with Archea's (1977, p. 129) assertion that "physical environment is an instrument which is used selectively to inhibit or facilitate the flow of interpersonal information." Potentially, assistive technologies can affect privacy through the rearrangement of personal space to accommodate the technology or through more subtly changing the perception of the home from private space into more public space. Tamm (1999) noted that older adults' perceptions of technologies introduced into the home environment have not been well studied. 


\section{Assistive Technologies}

Assistive technologies are defined as information-based health devices or systems installed in the RC residents' apartments or "homes". These technologies collect and share resident information to health care providers such as nurses or physicians. The purpose of assistive technologies are to help individuals with tasks they would otherwise be unable to do or to help individuals perform a given task more easily or safely (Cowan \& Turner-Smith, 1999).

Assistive technologies in these settings may include devices for: emergency communication; falls detection; gait and movement monitoring; cognitive reminder systems and medication management (Demiris et al, 2004; Dewsbury, Sommerville, Rouncefield \& Clarke, 2002; Miskelly, 2001). Examples of assistive technologies can be found both within the telehealth and "smart home" literature.

Early development in smart homes focused on homes designed with embedded non-obtrusive automatic functions and systems controlled by the user (Rialle, Duchene, Noury, Bajolle \& Demongeot, 2002; Stefanov, Zeungnam \& Bang, 2004). These early examples emphasized systems to enhance "comfort, energy savings and security for residents" (Stefanov et al., 2004, p. 228). Recent research in smart homes has begun to include telehealth applications and include non-obtrusive health monitoring applications (Rialle et al., 2002; Stefanov et al., 2004).

Smart home, assistive technologies are being installed within private residences (Magnusson \& Hanson, 2005; Rialle et al., 2002; Stefanov et al., 2004; Suzuki et al., 2004) and now also within residential care facilities (Rantz, Marek, Aud, Tyrer et al., 2005). The arguments for bringing these assistive technologies into community homes 
are to enhance residents quality of life; to help maintain them living at home and to reduce health care costs through prevention and early intervention (Magnusson \& Hanson, 2005; Rantz, Marek, Aud, Tyrer et al., 2005; Stefanov et al., 2004). In a cost analysis of assistive technologies to support older adults and their family caregivers $(\mathrm{n}=$ 34 families), researchers found that the average cost savings per family per year was 96,000 SEK (Swedish Crowns) or \$10,480 (Magnusson \& Hanson, 2005). The majority of estimated cost savings were a result of avoidance of nursing home placement (Magnusson \& Hanson, 2005).

The inclusion of these types of assistive technologies within residential care facilities is believed to be a mechanism to extend resident functional status and delay resident decline over time (Rantz, Marek, Aud, Tyrer et al., 2005). The inclusion of assistive technologies within the RC environment is one potential mechanism for supporting the Aging in Place model of care (Rantz, Marek, Aud, Tyrer et al., 2005). Effects on privacy

The ethics literature on information technologies within the home environment suggests that privacy should be an important ethical consideration for implementation and evaluation of these information systems (Bauer, 2001; Magnusson \& Hanson, 2003). "The private domain of the home becomes a highly porous, public node where medical information and communication technologies merge.” (Bauer, 2001, p. 140) Limited existing research on assistive technologies includes the concept of privacy in technology evaluation. The preliminary research in this area suggests that perceptions of privacy may be a barrier for the adoption of assistive technologies (Demiris et al., 2004; Magnusson \& Hanson, 2003). 
In a multi-national study of the implementation of information technologies for frail older adults in their own homes $(\mathrm{n}=39)$, issues of privacy arose with videophone technologies (Magnusson \& Hanson, 2003). Participants in the study described placing screens in front of the videophones to block visual access to the rest of the room (Magnusson \& Hanson, 2003). Additionally, participants described privacy concerns about the location of the videophones within the home (both in central areas such as the living room and in private areas such as the bedroom) and about who controls the opening of the communication line or if it was a continuous "open-line" (Magnusson \& Hanson).

Residents of a traditional assisted living facility indicated that privacy was a potential concern about using assistive technology with a video monitoring component (Demiris et al., 2004). Some of the residents did indicate that with changes to the video display, this assistive technology might be more acceptable (Demiris et al.). This finding suggests that the type of assistive technology and the type of information it collects and shares might be important factors in privacy concerns or in the decision to adopt.

Existing evaluation literature on assistive technologies often focuses on the potential benefits or usability of the technology and pays inadequate attention to the concerns of potential users or their willingness to adopt the technology. Several studies have suggested that not all older adults or families may uniformly benefit from assistive technologies (Magnusson \& Hanson, 2005; Rantz, Marek, Aud, Tyrer et al., 2005). Knowledge of how privacy concerns affect older adults' willingness to adopt new technologies is one necessary component for identifying which seniors might benefit from the technology. Without this understanding of privacy concerns and willingness to 
adopt technologies, researchers may not be able to effectively develop assistive technology interventions and target the appropriate populations.

Not only do interventions to improve or maintain older adult health status need to be implemented properly, but the interventions need to be the right intervention from the older adult's perspective. This study explored senior privacy concerns and the willingness to adopt assistive technology within a residential care living environment. The results of this study will help provide valuable knowledge for the development of assistive technology interventions and can inform the practice of health care providers, technology developers and policy makers.

Methods

Design

Following approval from the University of Missouri - Columbia Health Sciences Institutional Review Board, this study used a descriptive approach combining data collected from focus groups and individual interviews. A qualitative descriptive approach was chosen for this study because the research question pertained to the meanings of privacy and its effect on adoption of assistive technologies. The goal of this study was to produce a descriptive summary of an experience or decision event.

We selected focus groups initially because we were interested in the complex interaction between privacy and assistive technology adoption within residential care facilities. The focus group approach allowed us to explore belief, feeling and action in this area. We began with focus groups because we believed the group interaction could potentially generate a richer data set as participants can also respond to each others' beliefs, feelings and experiences, as well as describe their own. Prior work successfully 
used focus groups for in-depth probing of privacy for primary care patients (DeshefyLonghi, et al., 2004 and to explore attitudes and beliefs about assistive technology (Demiris et al., 2004).

After several potential respondents indicated that they were uncomfortable participating in focus groups on this topic, the research protocol was amended to include individual interviews. These individual interviews increased the subject diversity of the sample and were used to confirm data saturation from the focus groups' data.

\section{Sample: Size and Sampling Procedure}

This study used four focus groups ( $\mathrm{n}=11$ unique respondents). Although small, these numbers are consistent with the general rules for the number of participants and groups ( 3 to 12 participants per focus group and 3-6 focus groups per study) (Krueger \& Casey, 2000; Morgan, 1992). Data saturation, or when no new themes or issues emerged from group sessions, occurred after four group sessions. Individual interviews $(\mathrm{n}=3)$ were used to confirm data saturation.

Focus group members and individual respondents were recruited from older adults, ages sixty-five or older living in one of two mid-western RC facilities using different models of care (traditional versus Aging in Place). The residents were purposively sampled based on residential care facility model and resident physical independence level as judged by facility staff.

Participants were recruited using flyers in their mailboxes and on bulletin boards within the residence. Facility staff reminded residents of the focus group schedule, interview appointments, and referred interested residents to the research team. 


\section{Instrument}

A copy of the instrument is found in Appendix A. This instrument was a semistructured series of questions to guide the facilitator during the focus group and individual interview sessions. This study borrowed constant comparative analysis from the grounded theory tradition, and therefore as focus groups were conducted, the interim findings generated modifications to the interview guide.

The interview guide was developed in conjunction with the principles in Kruger's Developing Questions for Focus Groups (1998) and Stanfield's The Art of Focused Conversation (2000). Questions from the instrument were pilot tested during a focus group in an innovative intermediate care facility in November, 2005. The results of this pilot work were not included in the full study. No participants from the 2005 pilot focus group participated in this study.

Each group and individual session began with a discussion about privacy and their residential setting. This was followed by introduction of each technology (bed sensor, kitchen sensor, motion sensor, and fall detection sensor) and a discussion of initial reactions, and whether or not they would be willing to adopt (use) this technology. Appendix B provides additional detail on each of these technologies.

\section{Data Collection Procedure}

Following informed consent and a brief study introduction, the facilitator began the session using the interview guide. Each focus group and interview was audio taped and field notes were taken. Discussions lasted until the respondents had nothing new to add, usually lasting sixty minutes. Following the discussion period, the facilitator summarized the main points from the discussion and thanked the residents for their 
participation. This summary served as a member check to ensure that we captured what the participants intended.

\section{Method of Analysis}

Although many qualitative approaches to these data could have been considered, qualitative content analysis was chosen because of the descriptive goal of this study. A pre-determined coding scheme was not used for coding the data. Data codes and themes were inductively generated. The goal of the qualitative content analysis was a summary of the information gleaned from the analyses of data. Analysis of the data was performed by the PI and validity of interpretations was checked by other members of the research team. Interpretations were validated with each new focus group session. Following each focus group, transcript data were coded by line and sentence for descriptive (first-level) and theme (pattern) codes (Miles \& Huberman, 1994).

In grounded theory, in constant comparative analysis, data are analyzed in multiple levels, the individual text line, the clustering of ideas, and the pulling together of the concept or theory (Benoliel, 1996; Creswell, 1998). Because the focus of this study was the exploration of the meaning of privacy and its relationship with the adoption of assistive technologies rather than development of a theory of behavior, we used the first two levels of analysis, the individual text line (open coding) and the clustering of ideas or themes (axial coding) from the grounded theory tradition. Following open and axial coding, a conceptual map (Miles \& Huberman, 1994) was created. QSR N6 software aided the data analysis. 


\section{Findings}

This study was designed to better understand the relationship between privacy, residential setting and the adoption of assistive technologies. The meaning of privacy varied widely among the participants. Initial responses from participants neither uniformly rejected nor accepted the various technologies presented. Responses varied across residential care settings although subtle differences between the two settings helped illuminate community-level factors which were important in understanding the relationship between privacy and assistive technology adoption.

\section{The Meaning of Privacy}

Personal definitions of privacy ranged from a desire to be alone, a desire to control the information shared with others, a desire to control access to one's personal property and a desire to protect oneself from identity theft.

\section{Being Alone}

Several respondents indicated that privacy was related to being able to be alone or apart from others. One respondent linked being alone with physical separation from others or "not having someone invade your territory". Other respondents linked being alone with uninterrupted time for thinking, writing or reading. Most commonly, physical separation from others, such as going to their apartment, was described as a mechanism for achieving privacy. One respondent however described how anger could be used as a mechanism for achieving privacy in this context.

\section{Information Control}

For several participants, the meaning of privacy was tied to the ability to control the content of and recipient of information sharing. A list of topics considered private is 
available in Table 2. "My personal feelings about things that matter, about everyday subjects I'm very open with, but my own personal inner feelings or my financial matters, my physical matters, I keep to myself." Some respondents felt that information about their physical condition was also a private topic. "When you get older, you don't feel that safe on your feet....And you mean - is it - I have to announce that to everybody? ...I think that's the most private thing that you're really interfering with." Image capture (still or video) prompted strong negative responses from some respondents. "You'd feel like a puppet on a string...I don't want to be - something watching me. I want to be able to do whatever I feel like doing, when I feel like doing, where I feel like doing."

The recipient was also an important factor in information control. Although in general participants were willing to share their information with family, staff and health care providers, most participants indicated they wanted to be able to choose who received specific information.

Table 2: Private Information or Topics

\section{Private Information or Topics}

Sex

Feelings

Financial matters

Physical condition

Visual information (images - still or video)

Property or Territory Control

A few respondents also linked the ability to control access to their property or personal space to their personal definitions of privacy. Personal possessions were considered private. 
So in my room I do want my privacy. I want to know that I have my clothes here. I have my jewelry here. I have my little personal things. Yes, that's important to me. I don't want it to be on - anybody can just walk in my room and pick up whatever they'd like. No. I don't like it. Several respondents indicated the use of physical cues, such as "do not disturb" door hangers or the use of rituals, such as having friends or family call before visiting or making appointments, to control physical access to their rooms and themselves to protect their privacy.

Identity Theft

A few respondents also indicated that their definition of privacy was related to being able to secure their information to prevent identity theft. Concerns about the use of social security numbers as identifiers and computer security were raised as potential threats to privacy.

The Decision to Adopt an Assistive Technology Rarely did privacy concerns solely dictate respondents' adoption choices. For only a handful of respondents, their privacy concerns clearly guided their rejection of assistive technologies. "My privacy is too important to me." Most participants used a pragmatic approach to their technology needs and indicated that their perception of their need for the technology was the most important consideration in the decision to adopt an assistive technology. "Because if I need it, I would get it in a minute, if I could get there before my daughter did." For participants who had privacy concerns about the assistive technologies, the privacy concerns were not as important as their perception of their need 
for the technology. "But as far as privacy is concerned, I think the usefulness of the piece of equipment is the thing that determines that amount of privacy."

Factors that Influence the Perception of Assistive Technology Need

The perception of need for the technology was from the respondents' point of view and assumed that residents will have the opportunity to make a decision about using the technology rather than having the decision made for them. During the sessions, participants described a number of factors that influenced their perceptions of their need for assistive technologies. These factors are summarized in Table 3.

Respondents' perceptions of their own need of technology may not be consistent with the external opinions of family, friends, facility staff or their health care providers. Participants consistently described themselves as "healthy", "very healthy" or "blessed with good health all my life".

Table 3: Factors that Influence Self Perception of Need for Assistive Technology

\section{Factors that Influence Self Perception of Need}

Self perception of health

Physical condition

Mental \& emotional condition

Anticipatory living

Influence of family and friends

Influence of health care professionals

Physical environment

Technology type

Perceived redundancy of technology

Contrasting this self-perception of health though, were their statements regarding their health history and mobility difficulties. The respondents in this study listed a wide variety of health problems including serious cardiac and pulmonary conditions, degenerative processes such as osteoporosis and arthritis, and histories of joint 
replacements, long bone fractures and falls. Additionally, a few respondents relied on supplemental oxygen or mobility devices such as canes, walkers and mobilized chairs (scooters).

Respondents often said that older adults with cardiac or pulmonary conditions, cognitive disorders or mobility problems would be good candidates for these types of assistive technologies. However, these same respondents did not feel that they were personally in need of the assistive technologies. For example, one woman who had balance issues and a history of falls, described her health condition and then noted that she did not need a fall detection technology at this time. She described her current health concerns with 'Since I don't have any balance anymore, I have a plate in this leg also, I crushed the femur. Eleven screws.... I'm unbalanced with all of this in here [pointing to leg], and it makes me wobbly sometimes." Following this description, she noted that "I'd have to very dependent on my cane" before she would need the technology.

Very few respondents indicated that they currently needed the technology, but several thought that anticipated future changes in their physical, mental or emotional condition could influence their need for technology. "Well, now, as far as something like this is concerned, I would not object to it if there was a purpose for it, as in the case of this gentleman [with recent cardiac surgery]. He needed it because he was ill." Other respondents noted they were unlikely to adopt a technology not currently needed because of an anticipated future need. "I'm glad for the people who are fearful, and I think, in a way, it's a kind of fear of what's going to happen that makes you want - and I can't live that way. I never have." 
Participants also said that family and friends can influence their perceptions of needing the technology. One respondent gave a reverse example of how he influenced his sister to adopt an emergency communication service. Several noted the importance of their children's concerns when determining if they needed a service or a technology. A respondent also mentioned being influenced by the perceptions of their health care provider.

The residents' physical environment also affected their perceptions of needing assistive technologies. Several residents noted that their apartments were not appropriate for certain types of technology. The most commonly cited example was the lack of a stove which made the kitchen/stove top sensor irrelevant to them. The type of technology influenced the residents' perception of need. Few respondents saw a need for motion sensor technology even after being provided with sample case scenarios.

Likewise, some respondents viewed specific assistive technologies as redundant to other systems they already had. Examples given included: the stove top indicator light for the kitchen sensor; the emergency communication service for the fall detection sensor; and medical devices such as a Continuous Positive Airway Pressure (CPAP) machine and pulse oximeter for the bed sensor.

\section{Privacy as a Non-Constant Barrier for Assistive Technology Adoption}

Although the willingness to adopt assistive technologies was primarily driven by the residents' perceived need for the technology, privacy did play a role in assistive technology adoption. Privacy was a potential barrier to adoption. How privacy moderates the influence of self perception of need on assistive technology adoption is shown in Figures 1 and 2 below. Figure 1 illustrates how privacy can be a weak barrier 
to adoption when there are few individual-level and community-level privacy enhancing characteristics. In contrast, Figure 2 demonstrates how the presence of many individual and community privacy enhancing factors can present a strong barrier to assistive technology adoption.

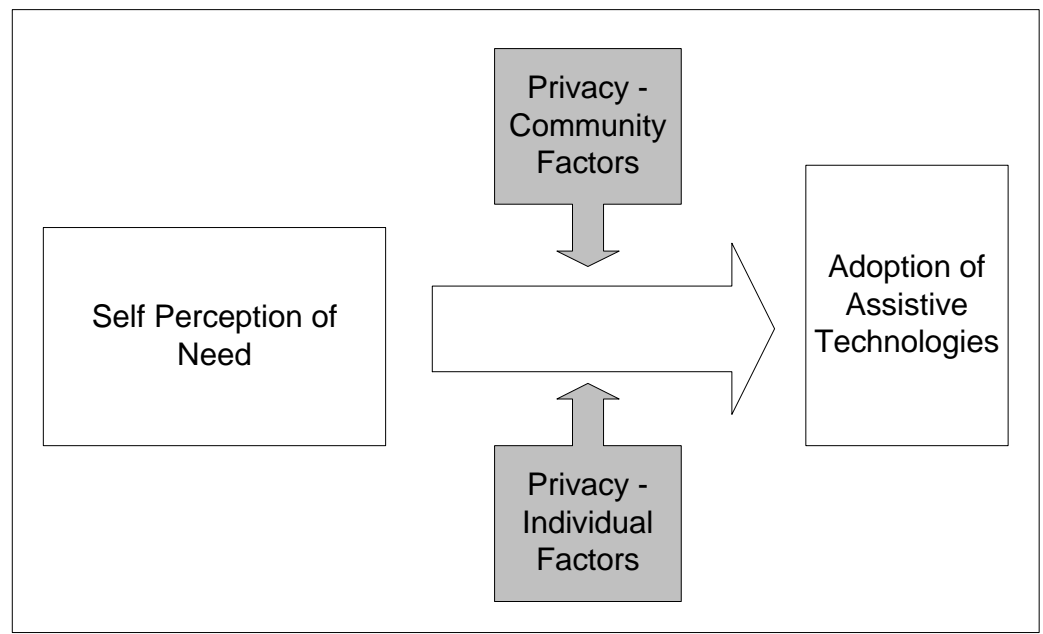

Figure 1 Privacy as a weak barrier to assistive technology adoption

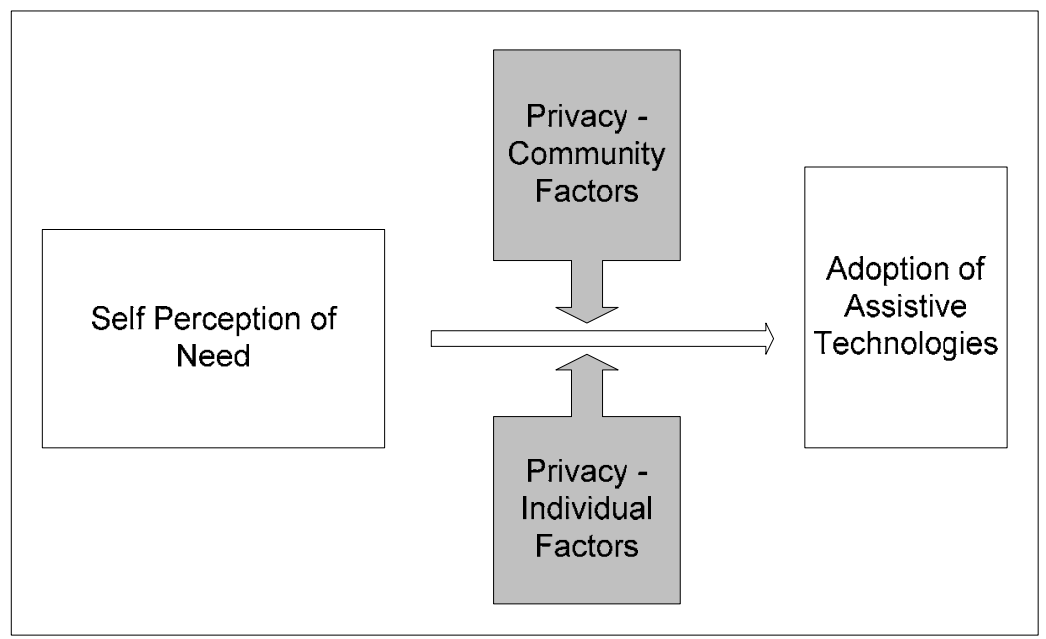

Figure 2 Privacy as a strong barrier to assistive technology adoption

For a few individuals in our study, the privacy factors would override any perception of need. 'It's just kind of against my feelings of privacy. I think that that's my prerogative to make those choices." For most individuals however, the perceived need for an assistive technology would outweigh their privacy concerns in making an 
adoption decision. Respondents did not uniformly accept all the assistive technologies shown and most indicated a preference for being able to select only the technology or technologies they perceived they needed. The two technologies mentioned the most often for privacy concerns were the video-based fall detection sensor and the motion sensor.

Several factors seemed to influence the privacy concerns about assistive technologies. These factors can broadly be divided into two categories: individual-level characteristics and community-level characteristics.

\section{Individual-level Characteristics}

Individual-level characteristics are summarized in Table 4. These characteristics are personality or behavior approaches used by the respondents. The presence of these characteristics was varied in both settings.

Table 4: Individual-level Privacy Characteristics

\section{Individual Privacy Characteristics}

Desire to be independent

Desire to control decisions

Value privacy

Hyperawareness of technology

Being "wide open"/willingness to share

Several characteristics enhanced privacy concerns. These characteristics included: a desire to be independent, a desire to control decisions, holding privacy as a value and a hyperawareness of the presence of technology. Respondents who described themselves as having these characteristics were more likely to have privacy concerns regarding the assistive technologies presented.

In contrast, one individual characteristic was associated with decreasing privacy concerns. This characteristic was a self-description of being "wide open". Participants 
with this individual characteristic saw themselves as having less privacy concerns overall because of these characteristic. One participant described himself as "I'm not as hyper on the privacy as a lot of the people, I know that. I've left myself wide open."

\section{Community-level Characteristics}

In addition to individual-level factors, community-level characteristics also influenced the privacy concerns of residents. Table 5 lists the community-level factors that emerged during resident discussions. Unlike single family home dwellings, residents with residential care facilities have a combination of both private and public spaces within their homes.

It's a community and uh, you know, you step out the door and you're in the public area...the corridors here are not only for you but they're for several other people so you have to respect that. You have to respect the fact that this is not yours totally. It's for everybody here. So it's a sharing of, of quarters, plus our own private little nooks and things.

Although the two settings have different models of care, the community-level characteristics did not appear to be related to the model of care used. These communitylevel characteristics were subtle differences in the way residents described their living environment and their relationships with other residents. In both settings, residents described their relationships with other residents and staff as friendly and as having mutual respect for personal boundaries. Residents from both settings indicated that they felt safe within their environment and felt that their privacy needs were respected. 
Table 5: Community-level Privacy Characteristics

\section{Community Privacy Characteristics}

Crisp boundaries between private and public space

Use of behavioral cues (knocking, calling, setting up times in advance)

Use of physical cues (door hangers)

Amount and depth of information shared

Number in community that share personal information

Aging in Place setting.

Within the Aging in Place model of care setting, community-level characteristics were more likely to enhance respondents' perceptions of having privacy. Residents within the Aging in Place setting more frequently described crisp physical boundaries between public and private space than did residents in the traditional model of care setting. One resident pointed out "the only boundary you have is your door, your entrance....take one step out your own door, you're in a public area."

Residents within the Aging in Place model setting frequently identified using physical cues such as door knob hangers and behavioral rituals such as appointment setting and phone calls before visits for managing privacy. One respondent said "You know if somebody put a do not disturb sign, I wouldn't go there. I wouldn't. That's their privacy." The use of behavioral cues such as pre-arranging visits for some residents even extended to their family members. "Even my daughters call."

Additionally, residents within this setting also were more likely to state that conversations with other residents were friendly but more superficial. "If anybody wanted to know what I've done and where I've been in my life, I don't mind to tell 'em. But somebody's not going to find out very much." Likewise, respondents in this setting revealed that they were selective in which residents they chose for information sharing. 


\section{Traditional model of care setting.}

In contrast to the well-defined boundaries in the other setting, residents of the traditional model setting noted that open apartment doors were normal within their setting and often other residents were invited to enter their homes at will. One woman shared "Well, like when colonoscopy on Friday and Thursday night I knew I'd be real sick and I called my neighbor and said the door will be open and I said check on me.” Another respondent recounted a resident asking him to fetch a set of spare keys from his apartment with "he said my door is always open. Just go right in and it's on such and such a place." A respondent summarized the relationship between privacy and their community as:

There are other times that I think a person needs to be able to give up some privacy for the good of the people around him. And to me that's important too. In fact, I think that may be a little more important than the first one [privacy as being alone].

Likewise, respondents from this setting, did not describe the use physical or behavioral cues as a means for maintaining privacy boundaries between residents.

Information sharing both in content and in recipient appeared to be broader in this setting based on the responses of the participants. "There's a lot of actual concern here and I think that that modifies this business of privacy. They're quite willing to talk about the rest of their families, and the things that have been happening to them and stuff like that." 


\section{Discussion}

\section{Dimensions of Privacy}

The findings from this study are consistent with earlier descriptive work on the dimensions of privacy. Respondents in this study used all four of the dimensions of privacy as described by Leino-Kilpi et al (2001). In their definitions of privacy, the participants indicated concerns about identity (psychological), information recipients (social), physical space and boundaries (physical) and shared information content (informational). Likewise, the participants noted the use of a variety of privacyenhancing mechanisms that spanned the physical, informational and social dimensions of privacy. In their discussions regarding assistive technologies, privacy concerns seemed to be centered in the psychological, informational, and physical dimensions of privacy rather than the social dimension.

Because respondents indicated that the relationship between privacy and assistive technologies is multi-dimensional, the possibilities for designing appropriate assistive technology interventions and systems are broader. For example, addressing concerns about psychological privacy or the protection of identity may mean assistive technology devices need to be made unobtrusive to the participant and undetectable to the casual observer. In contrast, informational privacy concerns may be addressed through development of individually resident-designed algorithms for information sharing. Understanding the nature of the privacy concerns of residents, will aid researchers, technology developers and policy makers in their practice. 


\section{Technology Acceptance Model}

The findings of this study partially fit within the Technology Acceptance Model (TAM). TAM was developed from the Theory of Reasoned Actions, a process whereby beliefs affect behavior. TAM isolates two categories of beliefs: 1) perceived usefulness and 2) perceived ease of use, which affect the intention to use technology (Davis, 1986). Perceived Usefulness is "the degree to which a person believes that using a particular system would enhance his or her performance" (Davis, 1999). Perceived Ease of Use is "the degree to which a person believes that using a particular system would be free of effort" (Davis, 1999). In TAM, these two beliefs have direct effect on "Intention to Use" a technology. TAM has been validated with various technologies and user groups and is one of the most influential models of technology acceptance and adoption (Al-Gahtani \& King, 1999; Hu, Chau, Sheng \& Tam, 1999; Yang \& Yoo, 2004).

Older adults' perceptions of their need for the assistive technology can fit with the Perceived Usefulness described in TAM. As the pragmatic perception of need generally outweighed privacy concerns for most respondents, the TAM model would seem to fit for most respondents. However, there were a few respondents for whom the perception of need was less important than their privacy concerns. For these respondents, TAM would not be appropriate. In this case, TAM is too simplistic to explain the intention of the respondents in our study.

\section{Limitations of This Study}

This study is limited in that it only explores older adults' willingness to adopt assistive technologies rather than their actual adoption of the technologies. Future work should re-examine this relationship between privacy, home environment and assistive 
technologies again when the technologies are beyond the development stage and are readily available for individual consumers.

Additionally, this work focused on the willingness to adopt by the seniors themselves rather than someone else making the adoption decision. Potentially, some facilities may make this choice for their residents. Conceivably, the decision to adopt the technology could also be made by their family members or health care providers.

Additional research is needed to understand the relationship between of privacy, living environment and assistive technologies when the adoption choice is outside of residents' control.

Residents in this study did bring up other potential barriers to technology adoption including cost and false alarms. These were not further explored because they were not seen by the participants to be relevant as a barrier due to privacy concerns, however this is a direction for future research.

\section{Conclusion}

The findings from this study indicate that privacy can be a barrier for older adults' adoption of assistive technologies; however their perception of their need for the technology may override their own privacy concerns. Interestingly, there appeared to be an inconsistency between the identified ideal candidates for the technology and their own health conditions. As one respondent suggested "some people might feel like they're losing a lot of their independence you know, having to rely on somebody and that is hard for a lot of people to accept." Perhaps denial of a potential problem is a mechanism to avoid making a decision about the technology. Acceptance of the technology could acknowledge their frailty to themselves and others. If so, older adults who might benefit 
the most from assistive technologies would be the least likely persons to adopt it. This has implications for both the design of assistive technology interventions and the evaluation of assistive technologies. Further exploration of the factors influencing older adults' perceptions of assistive technology need is necessary. 


\section{References}

Al-Gahtani, S. S., \& King, M. (1999). Attitudes, satisfaction and usage: Factors contributing to each in the acceptance of information technology. Behaviour \& Information Technology, 18(4), 277-297.

Altman, I. (1975). Privacy mechanisms and functions. In The Environment and Social Behavior: Privacy, Personal Space, Territory, Crowding (pp. 32-51). Monterey, CA: Brooks/Cole Publishing.

Angus, J., Kontos, P., Dyck, I., McKeever, P., \& Poland, B. (2005). The personal significance of home: Habitus and the experience of receiving long-term home care. Sociology of Health \& Illness, 27(2), 161-187.

Archea, J. (1977). The place of architectural factors in behavioral theories of privacy. Journal of Social Issues, 33(3), 116-137.

Bauer, K. A. (2001). Home-based telemedicine: A survey of ethical issues. Cambridge Quarterly of Healthcare Ethics, 10, 137-146.

Benoliel, J. W. (1996). Grounded theory and nursing knowledge. Qualitative Health Research, 6, 406-428.

California HealthCare Foundation. (1999). Medical privacy and confidentiality survey summary and overview. Retrieved 10/3/2005, from www.chcf.org/publications

Centers for Medicare and Medicaid Services. (2002). Health Insurance Portability and Accountability Act of 1996 (HIPAA). Retrieved 10/14/2002, from http://www.cms.hhs.gov/hipaa/default.asp 
Cowan, D., \& Turner-Smith, A. (1999). The role of assistive technology in alternative models of care for older people. In With Respect to Old Age - Research Volume 2 (pp. 325-346). London.

Creswell, J. W. (1998). Qualitative Inquiry and Research Design: Choosing Among Five Traditions. Thousand Oaks, CA: Sage Publications.

Davis, F. (1986). A technology acceptance model for empirically testing new end-user information systems: Theory and results. Unpublished doctoral dissertation, Cambridge, MA.

Davis, F. (1999). Perceived usefulness, perceived ease of use, and user acceptance of information technology. MIS Quarterly, 13(3), 319-340.

Demiris, G., Rantz, M. J., Aud, M. A., Marek, K. D., Tyrer, H. W., Skubic, M., et al. (2004). Older adults' attitudes towards and perceptions of "smart home" technologies: A pilot study. Medical Informatics \& The Internet in Medicine, 29(2), 87-94.

Deshefy-Longhi, T., Dixon, J. K., Olsen, D., \& Grey, M. (2004). Privacy and confidentiality issues in primary care: Views of advanced practice nurses and their patients. Nursing Ethics, 11(4), 378-393.

de Veer, A. J. E., \& Kerkstra, A. (2001). Feeling at home in nursing homes. Journal of Advanced Nursing, 35(3), 427-434.

Dewsbury, G., Sommerville, I., Rouncefield, M., \& Clarke, K. (2002). Bringing IT into the home. Retrieved 09/09/2005, from http://www.comp.lancs.ac.uk/computing/research/cseg/projects/dirc/index.htm 
Dewsbury, G., Taylor, B., \& Edge, M. (2001). The process of designing appropriate smart homes: Including the user in the design. Paper presented at the Equator IRC Workshop on Ubiquitous Computing in Domestic Environments, University of Nottingham, UK.

Ellefsen, B. (2002). Dependency as a disadvantage - patients' experiences. Scandinavian Journal of Caring Science, 16, 157-164.

Goldman, J., \& Hudson, Z. (1999). Promoting health protecting privacy: A primer. Retrieved 10/3/2005, from www.chcf.org/publications

Goldman, J., \& Hudson, Z. (2000). Virtually exposed: Privacy and E-health. Health Affairs, 19(6), 140-148.

Goodwin, L. K., Courtney, K. L., Kirby, J. D., Iannachione, M. A., \& Manley, T. (2002). A Pilot Study: Patients' Perceptions About the Privacy of Their Medical Records Online Journal of Nursing Informatics, 6(3).

Goold, S. D., \& Klipp, G. (2002). Managed care members talk about trust. Social Science \& Medicine, 54(6), 879-888.Hughes, M. (2004). Privacy in aged care. Australasian Journal on Ageing, 23(3), 110-114.

Hawes, C., Phillips, C. D., Holan, S., Sherman, M., \& Hutchinson, L. L. (2005). Assisted living in rural America: Results from a national survey. Journal of Rural Health, 21(2), 131-139. 
Health Resources and Services Administration. (2002). Projected Supply, Demand, and Shortages of Registered Nurses: 2000-2020: U.S. Department of Health and Human Services.

Hu, P., Chau, P., Sheng, O., \& Tam, K. (1999). Examining the technology acceptance model using physician acceptance of telemedicine technology. Journal of Management Information Systems, 16(2), 91-119.

Hughes, M. (2004). Privacy in aged care. Australasian Journal on Ageing, 23(3), 110114.

Krueger, R.A. (1998). Developing Questions for Focus Groups. Thousand Oaks, CA: Sage Publications.

Krueger, R. A., \& Casey, M. A. (2000). Focus Groups: A Practical Guide for Applied Research (3rd ed.). Thousand Oaks, CA: Sage Publications.

Leino-Kilpi, H., Valimaki, M., Dassen, T., Gasull, M., Lemonidou, C., Scott, A., et al. (2001). Privacy: A review of the literature. International Journal of Nursing Studies, 38(6), 663-671.

Lemonidou, C., Merkouris, A., Leino-Kilpi, H., Valimaki, M., Dassen, T., Gasull, M., et al. (2002). Nurses' and elderly patients' perceptions regarding autonomy, privacy and informed consent in nursing interventions in Greece. Reviews in Clinical Gerontology, 12(3), 191-204.

Lester, T. (March 2001). The reinvention of privacy. Atlantic Monthly, 27-39.

Lumpkin, J. R. (2000). E-Health, HIPAA and beyond. Health Affairs, 19(6), 149-151. 
Malcolm, H. A. (2005). Does privacy matter? Former patients discuss their perceptions of privacy in shared hospital rooms. Nursing Ethics, 12(2), 156-166.

Mangusson, L., \& Hanson, E. (2003). Ethical issues arising from a research, technology and development project to support frail older people and their family carers at home. Health and Social Care in the Community, 11(5), 431-439.

Mangusson, L., \& Hanson, E. (2005). Supporting frail older people and their family carers at home using information and communication technology: Cost analysis. Journal of Advanced Nursing, 51(6), 645-657.

Marek, K. D., Popejoy, L., Petroski, G., Mehr, D., Rantz, M. J., \& Wen-Chieh, L. (2005). Clinical outcomes of Aging in Place. Nursing Research, 54(3), 202-211.

Marek, K. D., \& Rantz, M. J. (2000). Aging in Place: A new model for long-term care. Nursing Adminstration Quarterly, 24(3), 1-11.

Marek, K. D., Rantz, M. J., \& Porter, R. T. (2004). Senior Care: Making a difference in long-term care of older adults. Journal of Nursing Education, 43(2), 81-83.

Miles, M. B., \& Huberman, A. M. (1994). Qualitative Data Analysis (2nd ed.). Thousand Oaks, CA: Sage Publications, Inc.

Miskelly, F. G. (2001). Assistive technology in elderly care. Age and Aging, 30, 455-458.

Monshi, B., \& Zieglmayer, V. (2004). The problem of privacy in transcultural research: Reflections on an ethnographic study in Sri Lanka. Ethics \& Behavior, 14(3), $305-312$. 
Morgan, D. (1992). Doctor-caregiver relationships. In B. Crabtree \& W. Miller (Eds.), Doing qualitative research (1 ed., pp. 205-227). Newbury Park, CA: Sage.

Phillips, C. D., Holan, S., Sherman, M., Spector, W., \& Hawes, C. (2005). Medicare expenditures for residents in assisted living: Date from a national study. HSR: Health Services Research, 40(2), 373-388.

Randers, I., \& Mattiasson, A.-C. (2000). The experiences of elderly people in geriatric care with special reference to integrity. Nursing Ethics, 7(6), 503-519.

Rantz, M. J., Marek, K. D., Aud, M. A., Johnson, R. A., Otto, D., \& Porter, R. (2005). Tiger Place: A new future for older adults. Journal of Nursing Care Quality, 20(1), 1-4.

Rantz, M. J., Marek, K. D., Aud, M. A., Tyrer, H. W., Skubic, M., Demiris, G., et al. (2005). A technology and nursing collaboration to help older adults age in place. Nursing Outlook, 53, 40-45.

Rantz, M. J., Marek, K. D., \& Zwygart-Stauffacher, M. (2000). The future of long-term care for the chronically ill. Nursing Adminstration Quarterly, 25(1), 51-58.

Ray-Degges, S. (1995). Privacy: The experiences of thirteen nursing home residents. Unpublished Dissertation, University of Missouri - Columbia, Columbia, MO.

Rialle, V., Duchene, F., Noury, N., Bajolle, L., \& Demongeot, J. (2002). Health "Smart" home: Information technology for patients at home. Telemedicine Journal and eHealth, 8(4), 395-409.

Rogers, E. (1995). Diffusion of Innovations (4th ed.). New York: The Free Press. 
Roosa, W. M. (1982). Territory and privacy Residents' views: Findings of a survey. Geriatric Nursing, 3, 241-243.

Rousch, C. V., \& Cox, J. E. (2000). The meaning of home: How it shapes the practice of home and hospice care. Home Healthcare Nurse, 18(6), 388-394.

Schopp, A., Leino-Kilpi, H., Valimaki, M., Dassen, T., Gasull, M., Lemonidou, C., et al. (2003). Perceptions of privacy in the care of elderly people in five European countries. Nursing Ethics, 10(1), 39-47.

Scott, P. A., Valimaki, M., Leino-Kilpi, H., Dassen, T., Gasull, M., Lemonidou, C., et al. (2003). Autonomy, privacy and informed consent 1: Concepts and definitions. British Journal of Nursing, 12(1), 43-47.

Shalala, DE. (1997). July 31, 1997 Protecting privacy of health information, Address to the National Press Club. Retrieved on October 14, 2002, from http://town.hall.org/radio/Club/071494_club_ITH.html

Spitzer, W. J., Neuman, K., \& Holden, G. (2004). The coming of age for assisted living care: New options for senior housing and social work practice. Social Work in Health Care, 38(3), 21-45.

Stanfield, R. B. (2000). The art of focused conversation: 100 ways to access group wisdom in the workplace (2nd ed.). Toronto, ON: The Canadian Institute of Cultural Affairs.

Stefanov, D. H., Zeungnam, B., \& Bang, W.-C. (2004). The smart house for older persons and persons with physical disabilities: Structure, technology 
arrangements and perspectives. IEEE Transactions on Neural Systems and Rehabilitation Engineering, 12(2), 228-250.

Straw, R. B., \& Smith, M. K. (1995). Potential uses of focus groups in federal policy and evaluation studies. Qualitative Health Research, 5, 421-427.

Suzuki, R., Ogawa, M., Otake, S., Izutsu, T., Tobimatsu, Y., Izumi, S.-I., et al. (2004). Analysis of activities of daily living in elderly people living alone: Single-subject feasibility study. Telemedicine Journal and e-Health, 10(2), 260-276.

Tamm, M. (1999). What does a home mean and when does it cease to be a home? Home as a setting for rehabilitation and care. Disability and Rehabilitation, 21(2), 49-55.

Westin, A. (1970). Privacy and Freedom. New York, NY: Atheneum.

Williams, A. (2002). Changing geographies of care: Employing the concept of therapeutic landscapes as a framework in examining home space. Social Science \& Medicine, 55(1), 141-154.

Williams, A. (2004). Shaping the practice of home care: Critical case studies of the significance of the meaning of home. International Journal of Palliative Nursing, 10(7), 333-342.

Wilson, K. B. (1996). What is assisted living? Journal of Long Term Care Administration, 24(3), 3-4.

Yang, H.-d., \& Yoo, Y. (2004). It's all about attitude: Revisiting the technology acceptance model. Decision Support Systems, 38, 19-31. 
Appendix A

Privacy and Adoption of Assistive Technology in Residential Care Facilities Focus Group Interview Guide

Background information:

Several types of assistive technologies will be described and displayed to participants during the focus group session beginning with question 7. These technologies may include: gait monitors, motion sensors, kitchen sensors, bed, chair or floor sensors and sensor equipment with video/picture capabilities.

Focus group session:

At the beginning of the focus group the group facilitator will introduce himself/herself, review the consent to participate in the study and the principles of group confidentiality. The group facilitator will ask the participants to give their first name and how long they have been a resident.

16. How do you define privacy?

a. Potential cue - what do you consider private here? (information, interactions with others, the ability to be yourself, etc?)

17. What are some of the most important elements of your personal sense of privacy?

a. Potential cue - what types of things or events take away your sense of privacy? What types of things or events strengthen your sense of privacy?

18. What are your initial thoughts about privacy within a residential care living facility such as the one you live in?

a. Potential cue - what is the first thought that comes to mind when you think about privacy here as opposed to other types of living arrangements?

19. Please describe some situations within this living environment that might make you worry about your privacy?

a. Potential cue - Have you had anything happen that you considered a violation of your privacy? This could include things about your personal information, your interactions with other people here, the ability to be yourself, etc)

20. What types of things might you do to protect your privacy while living here?

a. Potential cue - Have you done changed your routines or the arrangement of your apartment? Have you maybe held information back from people or only told them part of the story?

21. Assistive technologies are information-based technologies that collect and share health information with health care providers such as nurses or physicians. Some types of assistive technologies that are being developed for residential care settings include: emergency help, falls detection, physiological monitoring, cognitive reminder systems and medication management. What are your initial thoughts about using assistive technologies?

a. Potential cue - what do you think about when you hear about technology such as a device to detect whether or not a person has fallen in their apartment? 
22. Please describe situations in which [insert assistive technology name] could be beneficial to you or others?

a. Potential cue - Motion sensors could count how many times you've entered a room, say a bathroom at night for example - can you think times when gathering information like this could be helpful to you or to other people? What about other sensors and the information they might gather?

23. Please describe situations in which [insert assistive technology name] could be would not be helpful to you?

a. Potential cue - For example, stove top sensors are designed to detect when a stove burner has been left on accidentally. Some residents do not use their stoves and have unplugged them. For those seniors, stove top sensors are probably not so helpful. What about in your situation?

24. What types of concerns would you have about having [insert assistive technology name] in your room?

a. Potential cue - For example, some residents have expressed a concern about tripping over floor sensor mats? Would this be something you would worry about?

25. What are your initial thoughts about privacy and some of the assistive technologies shown here today?

a. Potential cue - Would any of these devices change your sense of privacy?

26. Please describe a situation in which you would not use an assistive technology device because of privacy concerns?

a. Potential cue - Some seniors in earlier studies have had concerns about using emergency call button necklaces because they felt that wearing these devices would share information about their health status with anyone who saw them. Can you think of situations with the technologies here that might raise similar concerns?

27. Please describe a situation in which you would use an assistive technology device despite privacy concerns?

a. Potential cue - For example, having a medication dispenser on the kitchen counter may alert visitors that you are taking medications, but you may feel the convenience of using the machine to take your medications on time outweighs your privacy concerns. What types of technological assistance would be more important than your privacy concerns?

28. Are some assistive technologies more of a privacy concern than others?

a. Potential cue - We've shown a number of assistive technologies today. Some which capture your image, such as the video-cameras, your health information, such as the bed sensor or information on your surroundings such as the stove top sensor. Does the type of technology or the information gathered change your privacy concerns?

29. How important is privacy in making decisions about using assistive technologies here?

a. Potential cue - Would your concerns about privacy be the deciding factor in whether or not you were to use a particular technology? 
30. We have talked a lot today about privacy and assistive technology. Is there anything we have not covered that you would like to add to our conversation?

Following the discussion, the facilitator will summarize the main points from the discussion and thank the residents for their participation. 
Appendix B

\section{Assistive Technologies Presented in this Study}

\begin{tabular}{|l|l|l|}
\hline $\begin{array}{l}\text { Type of } \\
\text { Technology }\end{array}$ & Description/Intended Use \\
\hline Bed sensor & $\begin{array}{l}\text { Bed sensors are designed to } \\
\text { monitor heart rate, respiration, and } \\
\text { restlessness and compare readings } \\
\text { with personal norms. }\end{array}$ \\
\hline Kitchen sensor & $\begin{array}{l}\text { Kitchen or stove top sensors are } \\
\text { designed to detect when a stove } \\
\text { burner has been left on accidentally } \\
\text { when no one is present in the } \\
\text { kitchen. This sensor combines a } \\
\text { heat sensor with a motion sensor }\end{array}$ \\
\hline Motion sensor & $\begin{array}{l}\text { Fall detection } \\
\text { sensor }\end{array}$ & $\begin{array}{l}\text { Motion sensors are designed to } \\
\text { detect motion within a room. One } \\
\text { potential use could be detecting } \\
\text { increases in nocturnal trips to the } \\
\text { bathroom. }\end{array}$ \\
\hline
\end{tabular}


VITA

Karen L. Courtney was born in Park Ridge, Illinois. After attending public schools in Illinois, New York and North Carolina, she received the following degrees: B.A. in Psychology from the University of North Carolina at Chapel Hill (1990); B.S.N. with Honors from the University of North Carolina at Chapel Hill (1996); M.S.N. from Duke University (2002); and Ph.D. in Nursing from the University of Missouri Columbia (2006). While a doctoral student, she held a pre-doctoral informatics fellowship from the National Library of Medicine at the University of Missouri Columbia. She has accepted a tenure-track position as an Assistant Professor at the University of Pittsburgh, Pittsburgh, Pennsylvania. 